\title{
Testing trait plasticity over the range of spectral composition of sunlight in forb species differing in shade tolerance
}

\section{Wang, Qing-Wei}

2020-09

Wang , Q-W , Robson, T M , Pieristè , M , Oguro , M , Oguchi , R , Murai , Y \& Kurokawa , $\mathrm{H} 2020$, ' Testing trait plasticity over the range of spectral composition of sunlight in forb species differing in shade tolerance ' , Journal of Ecology , vol. 108 , no. 5 , pp. 1923-1940 . https://doi.org/10.1111/1

http://hdl.handle.net/10138/327477

https://doi.org/10.1111/1365-2745.13384

acceptedVersion

Downloaded from Helda, University of Helsinki institutional repository.

This is an electronic reprint of the original article.

This reprint may differ from the original in pagination and typographic detail.

Please cite the original version. 


\section{Journal of Ecology}

DR QING-WEI WANG (0rcid ID : 0000-0002-5169-9881)

DR T. MATTHEW ROBSON (0rcid ID : 0000-0002-8631-796X)

Article type : Research Article

Editor $\quad$ : Kun-Fang Cao

Title: Testing trait plasticity over the range of spectral composition of sunlight in forb species differing in shade tolerance

Authors: Qing-Wei Wang ${ }^{1,2 *}$, T. Matthew Robson ${ }^{3}$, Marta Pieristè ${ }^{3,4}$, Michio Oguro' ${ }^{1}$, Riichi Oguchi $^{5}$, Yoshinori Murai ${ }^{6}$, Hiroko Kurokawa ${ }^{1 *}$

\section{Author affiliations:}

${ }^{1}$ Forestry and Forest Products Research Institute, 1 Matsunosato, Tsukuba, Ibaraki 305-8687, Japan

${ }^{2}$ CAS Key Laboratory of Forest Ecology and Management, Institute of Applied Ecology, Chinese Academy of Sciences, Shenyang 110016, China

${ }^{3}$ Organismal and Evolutionary Biology, Viikki Plant Science Centre (ViPS), University of Helsinki, 00014 Helsinki, Finland

${ }^{4}$ Normandie Université, UNIROUEN, Ecodiv URA/EA1293, IRSTEA, FR Scale CNRS 3730, Rouen, France

${ }^{5}$ Graduate School of Life Sciences, Tohoku University, 6-3 Aramaki Aza-Aoba, Aoba-ku, Sendai, Miyagi 980-8578, Japan

${ }^{6}$ Department of Botany, National Museum of Nature and Science, 4-1-1 Amakubo, Tsukuba, Ibaraki 305-0005, Japan

\section{*Co-corresponding authors:}

This article has been accepted for publication and undergone full peer review but has not been through the copyediting, typesetting, pagination and proofreading process, which may lead to differences between this version and the Version of Record. Please cite this article as doi: $\underline{10.1111 / 1365-2745.13384}$

This article is protected by copyright. All rights reserved 
Qing-Wei Wang (wangqingwei@iae.ac.cn; wangqw08@gmail.com; Tel: +86-(0)24-8397-0329);

Hiroko Kurokawa (hirokokurokawa@gmail.com; Tel: +81-(0)29-829-8223)

This article is protected by copyright. All rights reserved 


\section{Abstract}

1. Although sunlight is essential for plant growth and development, the relative importance of each spectral region in shaping functional traits is poorly understood, particularly in dynamic light environments such as forest ecosystems.

2. We examined responses of 25 functional traits from groups of 11 shade-intolerant and 12 understorey shade-tolerant forb species grown outdoors under five filter treatments differing in spectral transmittance: (1) transmitting c 95\% of solar radiation $(290-800 \mathrm{~nm})$; (2) attenuating ultraviolet-B (UV-B); (3) attenuating all UV; (4) attenuating all UV and blue light; (5) attenuating all UV, blue, and green light.

3. Our results show that UV-B radiation mainly affected the biochemical traits but blue light mainly affected the physiological traits irrespective of functional strategy, whereas green light affected both sets of traits. This would suggest that differentiation among suites of functional-trait responses proceeds according to light quality. Biomass accumulation was significantly increased by UV-A radiation (contrasting treatment (2) vs (3)) among shade-intolerant but decreased by blue light among shade-tolerant species: green and red light affected whole-plant morphological development differently according to functional groups. Shade-tolerant species were more plastic than shade-intolerant species in response to each spectral region that we examined except for UV-B radiation.

4. Synthesis. Our results show that differences in the spectral composition of sunlight can drive functional trait expression irrespective of total irradiance received. The different responses of functional traits between functional groups imply that shade-tolerant and intolerant species have adapted to utilize spectral cues differently in their respective light environments.

KEYWORDS: solar radiation; spectral composition; functional traits; phenotypical plasticity; shade tolerance; temperate forests; understorey species; light niche

This article is protected by copyright. All rights reserved 


\section{1 | INTRODUCTION}

Sunlight is essential to life on Earth. It supports plant growth and productivity by supplying the necessary energetic input for photosynthesis, and directly and/or indirectly affects carbon (C), nutrient and water cycles in terrestrial ecosystems (Leuchner, Hertel \& Menzel 2011). Sunlight in nature also provides cues for regulation of plant morphological, biochemical, and physiological traits: photoreceptors and plant pigments absorb the spectral regions of incoming solar radiation from ultraviolet (UV)-B $(280-315 \mathrm{~nm})$ to red light $(600-700 \mathrm{~nm})$, and through their response consequently modify ecosystem processes and diversity (Bornman et al. 2019). A better understanding of how sunlight controls plant traits is needed to accurately predict the response of ecosystem functioning to climatic change (e.g. changes in cloudiness, aerosols, and surface reflectivity), which is modifying the spectral composition of incident irradiance at the Earth's surface (Barnes et al. 2019).

Effects of sunlight on plant traits vary according to received irradiance and its spectral composition, and mainly depend on the activation of a combination of photoreceptors. In the visible spectrum, blue light $(400-500 \mathrm{~nm})$ and red light are the two most-effectively utilized wavelength regions for plant photosynthesis (Abidi et al. 2013). Blue light stimulates several photoreceptors such as cryptochromes (CRYs), phototropins (PHOTs) and photoreceptors of the zeitlupe family (Casal 2000; Lin 2000), in a coordinated response to promote photosynthetic efficiency (Hogewoning et al. 2010). Red light affects the development of photosynthetic apparatus by stimulating phytochromes (PHYs) (Smith 2000). Green light (500-600 nm) can act as a shade signal antagonistically to blue light, and can potentially drive leaf photosynthesis and increase plant growth, supplementing the effect of red light, because of its higher penetration in the leaf mesophyll (Terashima et al. 2009; Smith, McAusland \& Murchie 2017). In the UV spectrum, the portion of the UV-A radiation $(315-400 \mathrm{~nm}$ ) above $350 \mathrm{~nm}$ shares the same photoreceptors as blue light and similarly promotes phenolic metabolism (Wade, Sohal \& Jenkins 2003); whereas UV-A radiation below $350 \mathrm{~nm}$ and UV-B radiation are sensed by UVR8 (UV RESISTANCE LOCUS8) which regulates plant UV-B acclimation (e.g. flavonoid accumulation) (Casati et al. 2011; Rai et al. 2019) and may promote cross-resistance to multiple stresses (Jansen et al. 2019).

Since plants simultaneously receive light from multiple wavelength regions under ambient sunlight conditions, all these responses are likely to be coordinated through crosstalk between 
different photoreceptors which share a common set of signalling components (Casal 2000; Rai et al. 2019). Such integration may contribute towards optimising plant acclimation to changes in light environments, and to increase fitness, when one cue does not provide sufficient information to unequivocally define the environment and another one resolves this ambiguity (Casal \& Qüesta 2018). For instance, red light as a component of the solar spectrum increases photosynthesis and growth, but growth under monochromatic red light may result in low photosynthetic capacity, low maximum quantum yield of photosystem II $\left(F_{\mathrm{v}} / F_{\mathrm{m}}\right)$ and LMA, and impaired growth rate (Hogewoning et al. 2010).

The effects of each spectral region have been intensely studied in molecular and horticultural contexts. These studies showed that responses of plants to single spectral regions can be utilized to enhance crop production and nutritional value (Hogewoning et al. 2010; Casati et al. 2011; Morales et al. 2013; Brelsford et al. 2019; De Almeida, Herrera \& Tezara 2019; O'Hara et al. 2019; Rai et al. 2019). In this respect, UV-B radiation has received particular attention as the main regulator of phenolic-compounds accumulation in plants (Agati \& Tattini 2010), but lately evidence from experiments filtering the solar spectrum confirm that UV-A radiation and blue light are also important regulators of a suite of leaf biochemical traits overlapping with the UV-B response (Siipola et al. 2015; Rai et al. 2019). However, the extent to which these responses seen in lab or greenhouse studies persist in plants growing under ambient sunlight in an ecological context is uncertain, particularly for species growing in dynamic light environments such as forest understorey.

In temperate deciduous forests, understorey spectral composition varies greatly over the year and even during the day, due to sun angle, canopy phenology, and wavelength-selective absorption and reflection of photons by overstorey leaves (Leuchner, Hertel \& Menzel 2011; Hartikainen et al. 2018). To cope with such heterogenous light availability, it is expected that understorey species may have evolved light-dependent plasticity (the environmentally induced shift in a phenotype) (Schlichting \& Pigliucci 1998; Benito Garzón, Robson \& Hampe 2019). Several studies reported that understorey species acclimate to light conditions through adjustments of their traits related to leaf morphology (Kitajima \& Poorter 2010), biochemistry (Niinemets \& Kull 1998), physiology (He et al. 2019), plant architecture (Pearcy, Muraoka \& Valladares 2005), and biomass allocation (Westerband, Horvitz \& Gilliam 2017). There is conclusive evidence that although overall plasticity is generally lower in shade-tolerant species than shade-intolerant species, their traits are optimized for light capture (e.g. leaf morphology and chlorophyll content) 
(Valladares et al. 2000; Niinemets \& Valladares 2004; Portsmuth \& Niinemets 2007). Shade-intolerant species rely on enhanced physiological plasticity in utilizing captured light efficiently (e.g. net assimilation rate) in homogenous conditions (Valladares et al. 2002b; Riikonen et al. 2016). Most of these studies have focused on effects of visible light intensity and/or red to far-red ratio $(\mathrm{R} / \mathrm{Fr})$. However, others such as blue: red (B:R) and blue: green (B:G) light ratios also distinctly decrease from the overstorey to understorey due to the higher proportion of blue light absorbed than red and green light (Navrátil et al. 2007). By failing to consider all of the changes in spectral composition involved in sun-shade transitions, the results of these studies may potentially either over- or under- estimate the effects of spectral composition on understorey plant performance. For instance, the leaf morphology of shade-intolerant shrubland species from light-saturated habitats tend to lack plasticity to visible light relative to species from forest understories (Power et al. 2019); whereas shade-tolerant cocoa (Theobroma cacao) plants have higher plasticity in physiological and biochemical traits than morphological traits (De Almeida, Herrera \& Tezara 2019). A recent meta-analysis of plant responses to irradiance for 70 traits in 760 plant species shows that differences in plasticity between shade-tolerant and -intolerant species are generally small when considered over the entire range of trait responses to light (Poorter et al. 2019). Plasticity of plant-trait response to variation in composition of the solar spectrum from UV-B to red is still relatively unstudied in this context. The relative irradiance in these regions of the spectrum is strongly modified both by changes in the immediate environment (e.g. cloud cover) and the surrounding plant canopy, but the effect of these compositional shifts on plant traits is poorly understood.

The present study examines the role of solar radiation and its spectral composition in shaping plant traits. Forb species representing two plant functional types with different light capture strategies were selected: 11 common shade-intolerant species (widespread in open areas) and 12 shade-tolerant species (from forest understories). Our interest in the understorey herbaceous layer derives from its high species diversity and important contribution to ecosystem functioning and services in temperate forest ecosystems (Kumar et al. 2018). This study aims to answer three questions: 1) How are plant functional traits in shade-tolerant vs. intolerant species affected by specific regions of the solar spectrum which change with the spectral composition of sunlight in different environments? 2) Which functional traits respond with the greatest plasticity to spectral changes in sunlight? To answer these questions, we tested the hypothesis that, in terms of functional-trait values, those longer wavelength regions of the solar spectrum that we considered 
(i.e. green or red) affect leaf and whole-plant morphology, whereas the shorter wavelength regions (e.g. UV-B, UV-A and blue) determine biochemical and physiological traits; as inferred from the functions of the respective photoreceptors for these regions. The red/far-red ratio is not considered here, since it has already been studied in much greater detail than these shorter-wavelength regions. At the functional-strategy level, shade-tolerant species are adapted to shaded understorey conditions, in which blue light is depleted, and have traits to maximize light capture under light-limiting conditions; while shade-intolerant species may be adapted to a wider spectral range and have mechanisms to avoid shade and cope with excessive irradiance. From our experimental comparison, we can judge the phenotypic plasticity of these responses across a range of realistic spectral compositions that might be found between full sun and deep understorey shade.

This article is protected by copyright. All rights reserved 


\section{2 | MATERIALS AND METHODS}

\section{1 | Plant species and seedling preparation}

We selected 23 widespread common forb species from the two functional groups (see species list in Table S1), 11 shade-intolerant species (or light-demanding species) inhabiting open areas, and 12 shade-tolerant species naturally growing in the understorey in Ogawa Forest Reserve; a temperate forest dominated by Quercus serrata, Fagus japonica, and F. crenata, in the southern part of the Abukuma Mountains of central Japan $\left(36^{\circ} 56^{\prime} \mathrm{N}, 140^{\circ} 35^{\prime} \mathrm{E}\right.$, elevation 610 to $660 \mathrm{~m}$ asl). Seeds of shade-intolerant species were collected from Tsukuba Botanical Garden, National Museum of Nature and Science, Tsukuba, Japan $\left(36^{\circ} 00^{\prime} \mathrm{N}, 140^{\circ} 08^{\prime} \mathrm{E}\right)$, and those of shade-tolerant species from Ogawa Forest understorey. Seeds were collected from around 5-10 similarly healthy individuals per species, separated distant from each other by at least $2 \mathrm{~m}$. Seeds were dried at room temperature and stored at $4{ }^{\circ} \mathrm{C}$ until germination.

Following our preliminary experiment, seedlings of shade-tolerant and -intolerant species were prepared according to their mode of reproduction. Only two shade-tolerant species (Cryptotaenia canadensis subsp. japonica and Leucosceptrum stellipilum var. radicans) germinated sufficiently, thus we directly collected field seedlings for the remaining 10 shade-tolerant species from Ogawa Forest Reserve on 23 May 2018. Young plants of similar size with maximum 3 leaves were selected from 10 different forest patches $(30 \times 20 \mathrm{~m}$ in size, approximately 20-m distance from each other), between 8-10 individuals of each species per patch. Seedlings were carefully excavated with soil avoiding root damage, and gently put into moist seedling trays. They were then transported to a greenhouse of the Forestry and Forest Products Research Institute (FFPRI), Tsukuba $\left(36^{\circ} 00^{\prime} \mathrm{N}, 140^{\circ} 08^{\prime} \mathrm{E}\right)$, and transplanted into pots with volume of $438 \mathrm{~cm}^{3}(9 \times 7.6 \times 6.4 \mathrm{~cm})$ in trays $(51 \times 31 \times 5.3 \mathrm{~cm})$ on 24 May 2018. They remained under a mesh with a shade ratio of approximately $90 \%$ for a 30 -day light-acclimation period. Pots were filled with a soil mixture of compost soil, vermiculite, kanuma soil, and pumice $[6: 1: 2: 1(\mathrm{v} / \mathrm{v})]$, and kept equally moist by watering from beneath through the trays.

Prior to sowing of those species grown from seed, the seeds had been vernalized on wet filter papers for 4 days at $4{ }^{\circ} \mathrm{C}$ (in the dark). Seeds were sown on 25 May 2018 into pots in the same greenhouse, but without the shade mesh in ambient sunlight. All of trays were randomly rotated once a week to ensure that there were no initial differences in seedling size. Water was added to

This article is protected by copyright. All rights reserved 
trays every 3 days, and nutrients were supplied once a week with a commercial liquid fertilizer (N-P-K $=6-10-5 \%$, HYPONEX, Japan) (diluted concentration of $1.2 \mathrm{~mL} / \mathrm{L}, 7.5 \mathrm{~mL} / \mathrm{pot}$ ).

\section{2 | Design of the spectral attenuation experiment}

The spectral attenuation experiment was performed in a large unshaded common garden at FFPRI. Five spectral irradiance treatments were created by using specific plastic filters mounted on frames transmitting radiation: $(i)>280 \mathrm{~nm}$, with a fully transparent polythene film $(0.05 \mathrm{~mm}$ thick, 3904CF; Okura, Marugame, Japan), transmitting approximately 95\% of the whole solar spectrum; (ii) $>315 \mathrm{~nm}$, attenuating UV-B radiation $(280-315 \mathrm{~nm} ; 0.125-\mathrm{mm}$-thick polyester film, Autostat CT5; Thermoplast, Helsinki, Finland); (iii) $>400 \mathrm{~nm}$, attenuating all UV radiation (280-400 nm; 0.2-mm-thick Rosco E-Color 226 filter, Westlighting, Helsinki, Finland); (iv) >500 $\mathrm{nm}$, attenuating all UV and blue wavelengths (280-500 nm; 0.20-mm-thick Roscolux Supergel 312 filter); $(v)>580 \mathrm{~nm}$, attenuating all UV radiation and blue-green (BG) wavelengths (280-580 nm; 0.2-mm-thick Rosco E-Color 135 Deep Golden Amber filter) (Fig. 1).

The filters were attached to $1.2 \times 1.0 \mathrm{~m}$ wooden frames at approximately $20^{\circ}$ inclination, facing south. Additional filter pieces were attached to the East and West sides of frames as curtains, attenuating solar radiation early and late in the day. Filter height was adjusted to keep them suspended approximately 20-cm above the upper leaves of seedlings throughout the experiment. Spectrally neutral shade mesh of different transmittance ratios was added below the filters to ensure that seedlings received equivalent photosynthetically active radiation (PAR) irradiance across different treatments. The average PAR, determined using a quantum sensor (LI-190, Li-Cor Biosciences Inc, Lincoln, NE, USA), was 86\% lower than ambient sunlight under each frame (Table S2). This reduction in irradiance may decrease photoinhibition and photodamage to shade-tolerant species, and consequently make it easier for us to distinguish potential treatment effects rather than damage due to high irradiance.

The solar spectrum was measured under each filter, before and after affixing the shade mesh, under an almost completely clear sky at solar noon using a spectroradiometer (USR- 45DA; USHIO, Tokyo, Japan). (Fig. 1b, c). Biologically effective UV doses were calculated using five of the most relevant biological spectral weighting functions (BSWF), and spectral irradiances were calculated with R package 'photobiologyUV' (Aphalo, Kotilainen \& Davis 2019) (Table S2). The spectral irradiance under each frame was checked during the experiment to ensure that all filters retained their specified spectral attenuations until the end of the experiment using a Maya 2000 
Pro array spectrometer (Ocean Optics Inc., Florida, USA), recently calibrated for maximum sensitivity in the solar UV and PAR regions of the spectrum (same device used in Hartikainen et al., 2018).

The whole experiment was laid out in four replicate randomised blocks of filters, giving 20 filter-frames in total (Fig.1a). In total 575 similar-sized seedlings (one individual per pot) from 23 species were used in the experiment. 25 individuals per species (four individuals plus one spare per treatment), were randomly selected and divided among the 20 filter-frames on 23 June 2018 . Under the center of each frame, all plants were placed in two trays $(51 \times 31 \times 5.3 \mathrm{~cm})$ on a wooden shelf, which meant that exposure to diffuse solar radiation around the sides of the filters was minimal (the border was $20 \mathrm{~cm}$ ). The position of the pots was randomly rotated once a week to ensure that all seedlings grew in similar light conditions throughout the experiment. Water was automatically supplied using a purpose-built sprinkler system twice a day (once at 8:00 am and 7:00 pm for $60 \mathrm{~s})$. Nutrients were supplied with a HYPONEX liquid fertilizer $(1.2 \mathrm{~mL} / \mathrm{L}, 7.5$ $\mathrm{mL} /$ pot) once a week. Any dead individuals for each species and each treatment were noted and removed, and species mortality was calculated accordingly.

\section{3 | Environmental variables}

Ambient PAR, UV-B, and UV-A radiation were continuously measured and integrated over 15-min intervals using a quantum sensor (LI-190SA; LI-COR, Lincoln, NE) and two broadband UV-Cosine sensors (UV-B and UV-A) (sglux GmbH, D-12489 Berlin, Germany) respectively, recorded with a data-logger (LI-1400; LI-COR). Air temperature was recorded at 30-min intervals using a HOBO H8 Pro temperature logger (Onset Computer Corporation, Bourne, Massachusetts, USA), which was suspended approximately $20-\mathrm{cm}$ above the pots. The air temperature from the habitat of species origins were also recorded in the understory and open environments in Ogawa Forest Reserve, to compare the habitat of shade-tolerant and intolerant species.

\section{4 | Measurements of leaf optical properties, seedling morphology, and growth rate}

Leaf optical properties were examined under clear-sky conditions on sunny days on the newest fully expanded full-sun leaf, mid-way through the experimental period ( 39 days from the experiment's start), when seedlings were actively growing. The contents of leaf adaxial epidermal flavonols, anthocyanins, and leaf Chl per leaf area were assessed non-destructively, using the

Dualex Scientific ${ }^{+}$(FORCE-A, Orsay, France) under sunny clear-sky conditions around solar noon 
(Goulas et al. 2004). Meanwhile, the same measurements were also done in ten of the studied species (species code I01, I09, T02 04, T06 08, T11 12 in Table S1) growing in their native environment (the number of measured individuals per species was 5-10), in order to compare their optical properties with plants growing in the common garden. The quantum yield of photosystem (PSII) after dark adaptation $\left(F_{\mathrm{v}} / F_{\mathrm{m}}\right)$ and under the ambient sunlight $\left(F_{\mathrm{q}} / F_{\mathrm{m}}{ }^{\prime}\right)$ was measured using a portable Mini-PAM fluorometer (Heinz-Walz, Effeltrich, Germany) (Murchie \& Lawson 2013). Prior to $F_{\mathrm{q}} / F_{\mathrm{m}}$ ' measurement, a darkening clip was placed on the leaf for 1 hour to allow dark acclimation. All measurements were performed under clear-sky conditions on sunny days, in the morning at 9:00 -11:00 am and around solar noon at 1:00-3:00 pm.

Stem diameter, plant height, and crown spread (defined as the average lengths of two longest perpendicular spreads from edge to edge across the crown) were measured immediately prior to the experiment (23 June 2018), the half-way through (1 August 2018), and towards the end of the experiment (23 August 2018). Relative growth rate (RGR) was calculated (Oguchi, Hiura \& Hikosaka 2017) as:

$$
\mathrm{RGR}=\left[\ln \left(D_{j}^{2} \times H_{j}\right)-\ln \left(D_{i}^{2} \times H_{i}\right)\right] /\left(T_{j}-T_{i}\right)
$$

, where $D$ is the stem diameter, $H$ is the seedling height, $T$ is the time (day) and the subscripts ' $i$ ' and ' $j$ ' indicate the $i^{\text {th }}$ and $j^{\text {th }}$ day, respectively.

\section{5 | Measurement of leaf traits and biomass}

The plant traits listed in Table 1 were measured for each individual. Fully expanded sun leaves (2-4 leaves per individual) were collected under clear-sky conditions on a sunny day (27 August 2018) for biochemical and physiological measurements. After scanning, leaf samples were freeze-dried (FDU-1200, EYELA, Tokyo, Japan) for $16 \mathrm{~h}$. After grinding into a fine powder, leaf nitrogen $(\mathrm{N})$ and carbon $(\mathrm{C})$ concentrations were determined using an elemental analyser (Vario MAX cube, Hanau, Germany). The Folin-Ciocalteu Method was used to determine the concentration of total phenolics using tannic acid as a standard curve (Waterman \& Mole 1994). A proanthocyanidin assay was used to determine the content of the condensed tannins with a standard curve prepared using cyanidin chloride, a commercially available anthocyanidin (Julkunen-Tiitto 1985). An improved acetyl-bromide procedure (Iiyama \& Wallis 1990) was used to determine the lignin content, and the concentration of lignin was calculated from the fitted calibration curve (Fukushima \& Hatfield 2001). 
Another equivalent pair of leaves were sampled for measuring leaf morphological traits on 28 August 2018. After scanning, leaf area, leaf and petiole length were calculated using Fiji software (www.fiji.sc, ImageJ). Leaf mass per area (LMA) was determined based on leaf area and oven-dried weight of scanned leaves. Leaf toughness was measured at the middle point of the lamina, avoiding the main veins, using digital force gauge (DS2-50 N, IMADA, Toyohashi, Japan) together with a flat-ended cylindrical steel punch (2 $\mathrm{mm}$ in diameter). Plant organs (leaf, stem, root) were separated at the final harvest (29-31 August 2018). All leaves of each individual were scanned and total leaf area (TLA) was calculated including the leaves sampled for trait measurements. Leaf dry mass for biochemical and physiological measurements was determined according to the calculated LMA. the Aboveground- (ABDM), belowground(BEDM), and total-plant dry mass (TDM) were measured after dried at $60{ }^{\circ} \mathrm{C}$ for $48 \mathrm{~h}$. Measurement were not made of leaf traits and biomass for those shade-tolerant species where too many individuals died during the experiment to obtain a representative sample for these traits (see species mortality and measured trait list in Fig. S3).

\subsection{Statistical analyses}

For each functional trait (Table 1), linear mixed effect models (LME) were fitted with treatment and functional group (shade tolerant or intolerant species), and their interaction as fixed factors, and species and blocks as random grouping factors to reduce effects of plant size and frame position, using the nlme package (Pinheiro and Bates 2000). For this analysis, we used data from each individual plant, alive at the time of measurement. Data from the $1^{\text {st }}$ measurement were retained in the analyses for those species that by time of the $2^{\text {nd }}$ measurement had died. When the main treatment effect or interaction between treatment and functional group was significant $(P<$ $0.05)$, pairwise contrasts were used to further analyse the effects of specific wavelength regions (function glht, R package multcomp, Hothorn et al. 2008). The contrasts between the treatments: $>315 \mathrm{~nm}$ vs $>280 \mathrm{~nm},>400 \mathrm{~nm}$ vs $>315 \mathrm{~nm},>500 \mathrm{~nm}$ vs $>400 \mathrm{~nm},>580 \mathrm{~nm}$ vs $>500$ $\mathrm{nm}$, give the effect of UV-B, UV-A, blue light and green light, respectively; while the contrasts $>400 \mathrm{~nm}$ vs $>280 \mathrm{~nm}$ and $>580 \mathrm{~nm}$ vs $>400 \mathrm{~nm}$, give respectively the effect of $U V$, and blue and green (BG) light together; the contrast $>580 \mathrm{~nm}$ vs $>280 \mathrm{~nm}$ gives the effect of the spectrum from UV-B to green light (UV-BG). Benjamini-Hochberg (BH)'s methods (Benjamini and Hochberg 1995) was used to correct these $P$ values for multiple comparisons. For contrasts $\alpha$

$=0.10$ was used. Unpaired $T$-tests were used to analyse the difference in optical properties of the 
studied species between natural and common-garden conditions.

The plasticity of traits for each species and treatment was calculated using a plasticity index $(\mathrm{PI})=\left|\left(X_{i}-X_{j}\right) / \operatorname{sqrt}\left(X_{i}^{*} X_{j}\right)\right|($ Chan 2016). When making a contrast comparison, e.g. for UV-B effects, $X_{i}$ is the mean value of a given trait $(X)$ of a species from one treatment, ${ }_{i}$, (e.g. $\left.>315 \mathrm{~nm}\right)$, and $X_{j}$ is the mean value of the same trait of the same species from the other treatment, $j$. (e.g. $>280 \mathrm{~nm}$ ). The index offers the benefit that plasticity can be compared on the same scale across traits with a wide range of values, because PI is normalized based on the geometric mean. Response ratio was calculated using the natural log of the ratios for a contrast for each species. LME models were used to analyse effects of the trait category and spectral region on PI and response ratio, with the trait as a random factor; and effects of spectral region and functional group on plasticity of the pooled data, with species and traits as random factor. Furthermore, phylogenetic signals (Blomberg et al., 2003) were calculated to test whether the response ratio of traits and spectral treatments are more similar for related species using phytools package version 0.6-99 (Revell, 2012).

Partial redundancy analysis (pRDA; Legendre and Legendre 2012) was used to map the relative effects of spectral irradiance treatments (the actual irradiance measured under the filter and mesh) on plant traits based on data for each individual, with species as covariables, using the vegan package (Oksanen et al. 2018). Statistical significance was analysed by the Monte Carlo permutation methods and Bonferroni's test (permutations=999 times, $P<0.05$ ). Data were $\log$ transformed, and response variables were centred and standardised prior to the analysis. All statistical analyses were performed in R version 3.5.2 (R Core Team 2018).

This article is protected by copyright. All rights reserved 


\section{3 | RESULTS}

\subsection{Growth conditions and mortality}

The growth conditions in the summer season were characterized by strong sunlight and high temperature. Across the experimental period, $68 \%$ of the days reached high ambient irradiance $\left(\mathrm{PAR}>1500 \mu \mathrm{mol} \mathrm{m} \mathrm{m}^{-2} \mathrm{~s}^{-1}\right.$ ) (Fig. S1); while the daily mean and maximum air temperature were around 29.3 and $40.0{ }^{\circ} \mathrm{C}$, respectively (Fig. S2). These temperatures were slightly higher than those in the field habitat from which our shade-intolerant species grow $\left(23.5\right.$ and $32.2{ }^{\circ} \mathrm{C}$, respectively), but were much higher than the habitat of our shade-tolerant species (21.9 and $25.4{ }^{\circ} \mathrm{C}$, respectively) (Fig. S2). Such high temperature conditions may have partially confounded our treatment effects on plant survival, and caused leaf traits and biomass sampling at the final harvest to be impossible for 6 shade-tolerant species due to high mortality (Fig. S3).

\subsection{Responses of functional traits to spectral irradiance}

Most biochemical and physiological traits were significantly affected by the treatment, and some traits (flavonols, anthocyanin, $\mathrm{Chl}, F_{\mathrm{q}} / F_{\mathrm{m}}$, and $F_{\mathrm{v}} / F_{\mathrm{m}}$ ) were also affected by functional group, while the interaction was not significant (main effects of treatments and functional groups, Table 2). The further contrast analysis indicates that leaf contents of total phenolics and flavonols were significantly reduced, and lignin increased with the attenuation of UV-B, while condensed tannins were reduced by the attenuation of green light (Table 2; Fig. 2a-d); these effects were generally greater per unit of leaf area than per mass (Fig. S4 a-c). Anthocyanin content significantly increased and $F_{\mathrm{q}} / F_{\mathrm{m}}$ ' decreased when blue light was attenuated (Fig. 2e, i). The attenuation of green light not only affected biochemical traits, such as decreasing the contents of phenolics, lignin, and tannin, but also drove physiological traits, e.g. decreasing $\mathrm{N}$ concentration and increasing $\mathrm{C} / \mathrm{N}$ ratio (Fig. $2 \mathrm{~g}, \mathrm{~h}$ ). In addition, flavonol content for shade-intolerant species was lower in the experiment than in the field, but conversely it was higher for shade-tolerant species, while Chl and anthocyanin content tended to be similar between growing conditions (Fig. S5).

Leaf morphological traits were significantly affected by the treatment, with the exception of leaf toughness; this effect was consistent between functional groups (Table 2, Fig. 2). LDMC was significantly reduced by the attenuation of green light, and LMA by the attenuation of UV-B and green light (Fig. 2m, n).

The whole-plant morphological traits, except for stem diameter, varied significantly

This article is protected by copyright. All rights reserved 
depending on treatments and functional groups; the interaction effect was significant for TLA (Table 2, Fig. 2). The attenuation of UV-B radiation reduced TLA by $30 \%$ in shade-tolerant species, but not in shade-intolerant species (Fig. 2q). Petiole length of both functional groups increased when blue light was attenuated (Fig. 2p). Crown spread was significantly reduced by the attenuation of green light on the first measurement date, and by attenuation of UV-B radiation at the final harvest (Fig. S4e; Fig. 2r).

Growth and allocation were significantly affected by the treatments (except for RGR) and the effect on growth-related variables depended on functional group (Table 2). The three DM variables (ABDM, BEDM, and TDM) were generally reduced by the attenuation of UV-A radiation, and also BEDM by the attenuation of UV-B radiation, for shade-intolerant species, but were increased by the attenuation of blue light for shade-tolerant species (Fig. $2 \mathrm{u}-\mathrm{w}$ ).

Overall, the attenuation of multiple regions (UV and UV-BG) of the solar spectrum had pronounced effects on traits, while the attenuation of the BG region tended to have a weak effect on leaf and the whole-plant morphology, and growth (Table 2). Traits related to growth and the whole-plant morphology were the most responsive: they responded negatively to the attenuation of UV-B and UV-A radiation, and positively to the attenuation of blue/green light (Fig. S6). The extent of these responses was greater in shade-tolerant than shade-intolerant species. Furthermore, none of the studied functional traits showed significant phylogenetic signals for the responses to spectral treatments, except for that of $F_{\mathrm{q}} / F_{\mathrm{m}}$ 'to UV-A effects and that of $F_{\mathrm{v}} / F_{\mathrm{m}}$ to all contrasts (Table S3).

\subsection{Phenotypical plasticity of functional traits to selective attenuation of spectral irradiance}

Plasticity (PI) to the attenuation of each spectral region varied significantly depending on functional groups, traits, and their interaction in most cases (Fig. 3). In response to the attenuation of UV-B and UV-BG regions, the whole-plant morphology (particularly petiole length), leaf morphology (e.g. leaf toughness), DM, R/S, total phenolics, and tannins tended be more plastic for shade-intolerant than shade-tolerant species (Fig.3a, g; Fig. S7). In response to the attenuation of UV-A, green, UV, and BG regions, the PI in shade-tolerant species attained values similar to, or even-higher than, those of shade-intolerant species, e.g. for height, RGR, physiological (e.g. $F_{\mathrm{v}} / F_{\mathrm{m}}$, $F_{\mathrm{q}} / F_{\mathrm{m}}$, , and Chl) and biochemical traits (anthocyanin, total phenolics) (Fig. 3b, d-f; Fig. S7). Such responses to the attenuation of blue light were significantly affected by the interaction between traits and functional groups (Fig. 3c).

This article is protected by copyright. All rights reserved 
PI was significantly affected by spectral region, functional group and their interaction, when all traits were pooled (Fig. 3h). The overall trends indicate that shade-intolerant species were more plastic to the attenuation of UV-B and UV-BG regions than shade-tolerant species, but less plastic to the remaining regions.

\subsection{The relative effects of different spectral regions on functional trait expression}

Variation in all traits was significantly driven by spectral composition but differed according to functional group (Table S4; Fig. S8). For shade-intolerant species, UV-A radiation and unattenuated PAR (mainly red light) had the greatest effects among spectral regions (Fig. 4a; Fig. S9a): the former had a positive effect on most studied traits (especially crown spread, flavonols, leaf morphology, and dry mass), but a negative effect on anthocyanins, $F_{\sqrt{ }} / F_{m}$, and petiole length; while the latter had the opposite effects to UV-A radiation on these traits. Significant effects of UV-B radiation and blue light were detected for shade-tolerant species, with the two regions having synergistic effects on most plant traits; except for DM, TLA, and lignin where their effect was antagonistic (Fig. 4b; Fig. S9b). In addition, although red light was not selected for shade-tolerant species in the Monte Carlo permutation test (Table S4), it appeared to counter-balance the effect of blue/green light (Fig. S9b).

This article is protected by copyright. All rights reserved 


\section{4 | DISCUSSION}

\section{1 | General patterns of plant-trait response to spectral regions}

All of the spectral regions of solar radiation attenuated in our experiment, spanning from UV-B to green light, had the capacity to strongly affect a wide range of plant traits and that many of these effects were dependent on plant functional strategy for light capture (Table 2). By contrasting the general patterns of trait variation among spectral attenuation treatments, we found that most traits responses for shade-intolerant species were driven by UV-A radiation and by PAR beyond the regions our filters attenuated (mainly red light); while those of shade-tolerant species were driven by UV-B radiation and blue light which had synergistic effects on most plant traits (Fig. 4; Fig. S9). This dichotomy might reflect the difference in light-environments in the original habitats of the two functional groups, rather than phylogenetic relatedness among the studied species (Table S3). In forest understoreys there are typically drastic fluctuations in light intensity and spectral composition over short time periods compared with open habitats. The interception of sunlight by the forest canopy reduces its transmission passing from the overstorey to understorey. Understorey leaves may receive 50-300 sunflecks per day (most lasting $<10$ s) (Pearcy \& Calkin 1983). Moreover, canopy leaves differing in optical properties (sun vs. shade leaves) preferentially absorb red light, and even more so blue light (Hertel et al. 2012). Therefore, understorey species face light conditions with a modified spectrum including not only lower R/FR ratio, but also reduced blue: red $(B: R)$ and blue: green $(B: G)$ light ratios relative to the overstorey and open areas (Navrátil et al. 2007; Hertel et al. 2012). UV-B radiation is enriched in forest understorey shade relative to PAR due to its greater scattering by the atmosphere (Brown, Parker \& Posner 1994; Flint \& Caldwell 1998; Hartikainen et al. 2018). In comparison, shade-intolerant species living in open habitats tend to receive a relatively stable spectral composition (particularly in UV-A and PAR); beyond the transient effects of albedo, atmospheric features (e.g. clouds and aerosols) and time-of-day (e.g. at twilight).

\section{2 | Spectral regions are important in shaping plant functional trait expression}

As we hypothesized, plant functional trait expression was particularly affected by the attenuation of short-wavelength radiation, but different sets of traits predominately responded to different regions within this range. Hence, UV-B radiation mainly affected traits related to biochemistry (e.g. total phenolics, flavonols, and lignin), whereas blue light mainly affected 
physiological traits (e.g. $\mathrm{N}$ content and $F_{\mathrm{q}} / F_{\mathrm{m}}$ ) (Table 2; Fig. 2). Notably, green light tended to affect both these sets of traits, as well as driving whole-plant traits (e.g. crown spread) and leaf morphology (e.g. LMA) (Table 2; Fig. 2). The lack of significant interaction (except for TLA and biomass allocation) between treatments and functional groups suggested that the effect of spectral regions might be inherently similar between shade-intolerant and -tolerant species. However, the scale of this response tended to differ between the two groups, indicated by the significant effect of functional group on some components of each suite of traits (Fig. 2).

Although we created a similar set of spectral manipulations to previous studies (Siipola et al. 2015; Rai et al. 2019), those studies focussed on just a couple of model or horticulture species which do not necessarily reflect the diversity of plant-trait responses to spectral regions according to species functional strategies. Biochemical traits, particularly total phenolics and flavonol contents, significantly decreased in response to the attenuation of UV-B radiation (Table 2, Fig. 2). These trends agree with previous findings that accumulation of secondary metabolites is one of the most ubiquitous responses to UV-B radiation (Mazza et al. 2000; Searles, Flint \& Caldwell 2001), regulated by UVR8 (Morales et al. 2013; Jenkins 2017). However, we did not find evidence that these compounds responded to the attenuation of UV-A/blue light, which are also known to regulate phenolic compound accumulation through CRYs in model plants (Siipola et al. 2015; Brelsford et al. 2019; Rai et al. 2019). Among physiological traits, there was a distinct decrease in $\mathrm{N}$ content in response to the attenuation of blue light, while Chl content only decreased slightly, consistently with the response reported in other field experiments, e.g. in Scots pine (Sarala et al. 2009). Compared with model plants, wild species have adapted a set of traits appropriate for the characteristic spectral regions and/or other environmental factor defining their habitats (Oguchi et al. 2017; Wang et al. 2016). The responses of wild species therefore may not always correspond to the spectral responses attributable to photoreceptors identified from studies under controlled conditions with model species.

Whole-plant morphology, especially TLA, and biomass allocation significantly differed between our two functional strategies depending on spectral region (Table 2). Such differentiation indicates that the most important difference between shade-tolerant and -intolerant species may not be in their biochemical and physiological traits, but in the efficiency of their light interception and resultant carbon assimilation, giving them a selective advantage in those light environments associated with their respective habitats. For instance, the key light-capture trait TLA of shade-tolerant species was reduced by the attenuation of UV-B (part of the spectrum that is 
relatively enriched in forest understoreys as discussed above); but with respect to shade-intolerant species, both UV-B and PAR irradiances in our treatments were relatively low compared to open habitats. Hence, expanding crown spread would contribute to light capture (Liu et al. 2018). Furthermore, biomass accumulation was significantly decreased by the attenuation of UV-A among shade-intolerant but increased by the attenuation of blue light among shade-tolerant species (Table 2, Fig. 2), which may reflect their light utilization strategies. Shade-tolerant species does not necessarily adopt a strategy which maximizes growth or light interception as shade-intolerant species typically do (Power et al. 2019). Although blue light is valuable to plants for improving photosynthetic performance (Hogewoning et al. 2010), it is also involved in multiple signaling pathways which themselves demand carbon (e.g. stomatal opening) (Huche-Thelier et al. 2016). Shade-intolerant species need to maximize light capture even utilizing UV-A radiation when growing under low irradiance, facilitated by accumulating less flavonoids and allowing greater penetration of UV-A to the mesophyll (Turnbull, Barlow \& Adams 2013).

We found some functional traits to be regulated by multiple spectral regions, not only those corresponding to our expectations. For instance, $\mathrm{N}$ content and biochemical accumulation (e.g. total phenolics and tannin) decreased in response to the attenuation of green light, suggesting a role of green light in promoting photosynthetic capacity and biochemical responses. Green light generally penetrates deeper into the leaf mesophyll than blue and red light (Terashima et al. 2009) and may contribute to the optimization of resource-use efficiency and plant productivity in the forest understorey, where green light is relatively enriched. The combined effects of multiple regions can be synergistic or antagonistic (Table 2), perhaps due to the overlapping action spectra of photoreceptors. It is well documented that CRYs absorption spectrum spans from UV to green light (280-600 nm) (Banerjee et al. 2007) and overlaps potentially with UVR8 (280-350 nm) (O'Hara et al. 2019), PHOTs (315-500 nm) (Briggs \& Huala 1999), and PHYs (300-780 nm) (Shinomura et al. 1996). However, the way that multiple regions of the spectrum combine to produce plant trait responses in the field is yet to be well described. Specifically, in our study the "UV effect" tended to be distinct from UV-B and UV-A radiation, implying that both spectral regions affect plant traits in the same direction under relatively low irradiance (Table 2). A possible explanation for this is that the UVR8 action spectrum extends through the UV-B into the UV-A region (Morales et al. 2013). On the other hand, the interactive effect between blue and green light is complex. Green light has similar photomorphogenic effects on plants to those mediated by CRYs under blue light, which generally acts as a 'sun-type' cue (Bouly et al. 2007). 
In contrast, green light can also have reversible effects acting as 'shade' cues, mediated by uncharacterized green-light photoreceptors (Smith, McAusland \& Murchie 2017). It follows that the characteristic effects we found of blue and green regions individually were apparent in some biochemical and physiological traits, but not others (e.g. anthocyanin, crown spread, and LMDC), as indicated by the inconstant 'BG' effect among traits (Table 2). Previous studies have obtained similar results, for instance, green light antagonizes blue light-stimulated anthocyanin synthesis (Banerjee et al. 2007) and petiole elongation (Zhang, Maruhnich \& Folta 2011).

\section{3 | Differences in plasticity to spectral regions between functional groups}

Overall, plasticity was lower in shade-tolerant species than shade-intolerant species in response to the spectrum of sunlight (UV-BG region in Fig. 3h), consistent with the conclusions of many preceding studies (Valladares et al. 2002a; Niinemets \& Valladares 2004; Riikonen et al. 2016). However, considering light quality, the plasticity of shade-tolerant species was significantly higher than that of shade-intolerant species in response to the attenuation of single regions (UV-A, blue and green light) except for UV-B radiation (Fig. 3h; Fig. S7). This implies that shade does not represent a stress for understorey species that are adapted to low light conditions, a finding that diverges from previous studies that follow the resource limitation hypotheses (Valladares et al. 2000; Valladares et al. 2002a; Niinemets \& Valladares 2004; Portsmuth \& Niinemets 2007; Riikonen et al. 2016). To the best of our knowledge, this study is the first to report spectral region-dependency of plasticity between species representing two contrasting functional strategies for light capture.

Plasticity to spectral regions may confer a selective advantage on shade-tolerant species, but be unnecessary for shade-intolerant species. As discussed above, in forest understoreys both light quantity and quality are dynamic, varying between canopy shade (enriched in green light) and brief sunflecks (comparatively high blue light) (Leuchner, Hertel \& Menzel 2011; Hartikainen et al. 2018). High physiological plasticity to specific spectral regions offers understorey plants the potential to use the rapid changes in spectral composition as cues in the dynamic understory light environment, allowing efficient utilization of sunflecks (Pearcy 1994; Way \& Pearcy 2012), e.g. rapid photosynthetic activation and stomatal opening in response to blue light. Similar results were reported for open-area species and understorey species across forest-shrubland boundaries, with the former being less plastic (Power et al. 2019). Furthermore, Lei and Martin (1998) found that overstorey species responded consistently to changes in total irradiance rather than light quality 
(R/Fr ratio) (Lei \& Lechowicz 1998). However, we report one exception that shade-intolerant species were plastic to UV-B (Fig. 3h). This exception may be related to the potentially harmful effects of high UV-B irradiance in open-habitats which can induce growth inhibition and DNA damage (Wang, Hidema \& Hikosaka 2014; Wang et al. 2016).

Differentiation among suites of functional traits may be reflected by functional strategies to cope with respective light habitats (Valladares \& Niinemets 2008). For shade-tolerant species, it has been proposed that the capacity of a plant species to live in the understorey depends on their maintenance of a positive net carbon balance under low light (the Carbon Gain Hypothesis, (Givnish 1988)), or alternatively that they tolerate those stresses that interact with light availability (the Stress Tolerance Hypothesis, (Kitajima 1994)). In the present study, we report higher plasticity for shade-tolerant than -intolerant species not only in morphological and physiological traits, which are related to light interception and carbon gain maximization, but also in biochemical variables, which link to photoprotection and the resistance to herbivory and disease (Fig. S7). These results suggest that the hypothesized carbon gain efficiency and stress tolerance strategies are not mutually exclusive but essential for species in the forest understorey (as reviewed by Valladares and Niinemets 2008). This allows species with different suites of functional traits to occupy shaded habitats while performing different ecosystem functions. Shade can affect understorey plant life in multiple ways by creating complex environmental settings for ecosystem dynamics, including abiotic (e.g. temperature and humidity) dynamics, plant - plant and - animal interactions (Valladares et al. 2016). Differences in investments in defense and carbon gain by understorey species may highlight the variety of pathways towards adaptation to multiple combinations of selective factors. Furthermore, such diversity of trait plasticity may promote understorey species coexistence through enhancing stabilizing niche differences and generating competitive trade-offs between species (Turcotte \& Levine 2016; Valladares et al. 2016; Perez-Ramos et al. 2019).

For a given shade-intolerant species growing in an open area, fitness in a dense and productive plant community largely depends on resource competition for space and light (Grime 1973; Craine \& Dybzinski 2013). For instance, higher plasticity in growth and allocation among shade-intolerant species (Fig. 3; Fig. S7) should improve their capacity for interspecific competition. Plasticity in petiole length (Fig. 3) has been considered as one of the most important traits allowing herbaceous species to respond to light through elongating, bending and twisting (Pearcy, Muraoka \& Valladares 2005), however, such high-cost plasticity may constrain 
physiology and biochemical process in open areas, which are also generally nutrient-poor relative to forest understoreys (Hendry 2016; Power et al. 2019).

Caution is required in drawing general conclusions from our shade-tolerant species group, since nearly half of the studied species suffered high mortality during the experiment (Fig. S3). This might imply that the remaining species were adapted to cope with warm temperatures and our baseline irradiance. For instance, the lower flavonol accumulation among shade-intolerant species in the common-garden experiment than in the field may constitute a response to the relatively low irradiance, while the opposite pattern for the shade-tolerant species may be explained by the greater temperature fluctuations in the experiment and comparatively low irradiance in their native environment (Fig. S5). Since temperature interferes with photoreceptor responses known to be involved in leaf pigment accumulation (Coffey and Jansen 2019; Pescheck and Bilger 2019), the warmer temperatures in the common-garden experiment than that in the native habitat of these species might modulate some of these responses, particularly in the shade tolerant species. If so, this may skew the pattern of results for shade tolerant species, which may be more like those of shade-intolerant species, making the differences between the groups smaller.

This article is protected by copyright. All rights reserved 


\section{CONCLUSIONS}

Our study demonstrated that, at equivalent PAR, each spectral region of sunlight affected plant traits of the 23 species representing shade tolerant or -intolerant strategies. Different sets of traits typically responded to different spectral regions. Hence, UV-B radiation affected biochemical traits and blue light mainly affected physiological traits; whereas green light tended to drive both sets of traits, and to affect plant morphology in a functional-group-specific manner. Whole-plant morphology, growth and biomass allocation of shade-intolerant species were plastic in response to UV-B radiation and to the whole spectrum (UV-BG); while shade-tolerant species had a relatively high plasticity to UV-A, and all UV radiation, plus blue and green light in most traits; including those related to physiology and biochemistry. This divergence between the trait responses of functional groups associated with these two ecological strategies may reflect their adaptation to the respective light environments in their native habitats. Diverse plasticity among suites of traits within functional groups may also promote species coexistence across heterogenous light environments in forest understoreys, by increasing niche differentiation or by generating competitive trade-offs between species.

This article is protected by copyright. All rights reserved 


\section{ACKNOWLEDGMENTS}

We thank Drs Kouki Hikosaka, Qingming Han for valuable comments, and Dr. Jun Hidema for spectral equipment support, Drs. Mitsue Shibata and Tamotsu Sato for facilities at FFPRI, and Nobuko Hirai, Masako Hosoi, Yasuko Ogane, Hiroko Shiomi, Rie Takaya for their helps of laboratory works. Q.-W Wang is grateful to the Japan Society for the Promotion of Science (JSPS), Japan for awarding of JSPS Post-doctoral Research Fellowship for Foreign Researchers in Japan (FY 2017-2019). This study was supported by KAKENHI (17F17403) to QWW and HK, and by KAKENHI (17H03736) to HK, and by the CAS Young Talents Program to QWW. TMR was supported by Academy of Finland decisions \#304519 and \#324555 and MP by a grant from the Region "Haute-Normandie" through the GRR-TERA SCALE (UFOSE Project).

\section{DATA AVAILABILITY STATEMENT}

The data that support the findings of this study are available in Dryad with the identifier [data DOI..].

\section{AUTHOR CONTRIBUTIONS}

QWW, HK, and TMR conceived and designed the experiment. QWW, YM, and HK collected seeds and seedlings for the experiment. QWW carried out the growth experiment and performed most trait measurements and harvest. QWW, TMR, and MP measured spectrum and leaf optical properties. RO gave the suggestion on the experimental design and laboratory support. QWW, MO, and HK provided statistical analysis. QWW wrote the draft of the manuscript, and the remaining coauthors did the revision.

This article is protected by copyright. All rights reserved 


\section{REFERENCES}

Abidi, F., Girault, T., Douillet, O., Guillemain, G., Sintes, G., Laffaire, M., Ben Ahmed, H., Smiti, S., Huche-Thelier, L. \& Leduc, N. (2013) Blue light effects on rose photosynthesis and photomorphogenesis. Plant Biology (Stuttgart, Germany), 15, 67-74.

Agati, G. \& Tattini, M. (2010) Multiple functional roles of flavonoids in photoprotection. New Phytologist, 186, 786-793.

Aphalo, P.J., Kotilainen, T.K. \& Davis, G. (2019) Photobiology UV software package. https://www.r4photobiology.info/. Last updated in April 2019.

Banerjee, R., Schleicher, E., Meier, S., Viana, R.M., Pokorny, R., Ahmad, M., Bittl, R. \& Batschauer, A. (2007) The signaling state of Arabidopsis cryptochrome 2 contains flavin semiquinone. Journal of Biological Chemistry, 282, 14916-14922.

Barnes, P.W., Williamson, C.E., Lucas, R.M., Robinson, S.A., Madronich, S., Paul, N.D., Bornman, J.F., Bais, A.F., Sulzberger, B. \& Wilson, S.R. (2019) Ozone depletion, ultraviolet radiation, climate change and prospects for a sustainable future. Nature Sustainability, 1.

Benito Garzón, M., Robson, T.M. \& Hampe, A. (2019) $\Delta$ Trait SDMs: species distribution models that account for local adaptation and phenotypic plasticity. New Phytologist, 222, 1757-1765.

Benjamini, Y. \& Hochberg, Y. (1995) Controlling the false discovery rate: a practical and powerful approach to multiple testing. Journal of the Royal statistical society: series B (Methodological), 57, 289-300.

Blomberg SP, Garland T, Jr., Ives AR. 2003. Testing for phylogenetic signal in comparative data: behavioral traits are more labile. Evolution 57: 717-745.

Bornman, J.F., Barnes, P.W., Robson, T.M., Robinson, S.A., Jansen, M.A.K., Ballaré, C.L. \& Flint, S.D. (2019) Linkages between stratospheric ozone, UV radiation and climate change and their implications for terrestrial ecosystems. Photochemical \& Photobiological Sciences, 18, 681-716.

Bouly, J.-P., Schleicher, E., Dionisio-Sese, M., Vandenbussche, F., Van Der Straeten, D., Bakrim, N., Meier, S., Batschauer, A., Galland, P. \& Bittl, R. (2007) Cryptochrome blue light photoreceptors are activated through interconversion of flavin redox states. Journal of Biological Chemistry, 282, 9383-9391.

This article is protected by copyright. All rights reserved 
Brelsford, C.C., Morales, L.O., Nezval, J., Kotilainen, T.K., Hartikainen, S.M., Aphalo, P.J. \& Robson, T.M. (2019) Do UV-A radiation and blue light during growth prime leaves to cope with acute high light in photoreceptor mutants of Arabidopsis thaliana? Physiologia Plantarum, 165, 537-554.

Briggs, W.R. \& Huala, E. (1999) Blue-light photoreceptors in higher plants. Annual Review of Cell and Developmental Biology, 15, 33-62.

Brown, M.J., Parker, G.G. \& Posner, N.E. (1994) A survey of ultraviolet-B radiation in forests. Journal of Ecology, 82, 843-854.

Casal, J.J. (2000) Phytochromes, cryptochromes, phototropin: photoreceptor interactions in plants. Photochemistry and Photobiology, 71, 1-11.

Casal, J.J. \& Qüesta, J.I. (2018) Light and temperature cues: multitasking receptors and transcriptional integrators. New Phytologist, 217, 1029-1034.

Casati, P., Campi, M., Morrow, D.J., Fernandes, J.F. \& Walbot, V. (2011) Transcriptomic, proteomic and metabolomic analysis of UV-B signaling in maize. BMC Genomics, 12, 321.

Chan, J.P. (2016) The plasticity of functional traits in the Dipterocarps of Borneo. Master Dissertations and Theses in Biological Sciences., University of Nebraska - Lincoln.

Coffey, A. \& Jansen, M. A. K. (2019). Effects of natural solar UV-B radiation on three Arabidopsis accessions are strongly affected by seasonal weather conditions. Plant Physiology and Biochemistry 134, 64-72.

Craine, J.M. \& Dybzinski, R. (2013) Mechanisms of plant competition for nutrients, water and light. Functional Ecology, 27, 833-840.

De Almeida, J., Herrera, A. \& Tezara, W. (2019) Phenotypic plasticity to photon flux density of physiological, anatomical and growth traits in a modern Criollo cocoa clone. Physiologia Plantarum, 166, 821-832.

Flint, S.D. \& Caldwell, M.M. (1998) Solar UV-B and visible radiation in tropical forest gaps: measurements partitioning direct and diffuse radiation. Global change biology, 4, 863-870.

Fukushima, R.S. \& Hatfield, R.D. (2001) Extraction and isolation of lignin for utilization as a standard to determine lignin concentration using the acetyl bromide spectrophotometric method. Journal of Agricultural and Food Chemistry, 49, 3133-3139.

Givnish, T.J. (1988) Adaptation to sun and shade: a whole-plant perspective. Functional Plant Biology, 15, 63-92.

This article is protected by copyright. All rights reserved 
Goulas, Y., Cerovic, Z.G., Cartelat, A. \& Moya, I. (2004) Dualex: a new instrument for field measurements of epidermal ultraviolet absorbance by chlorophyll fluorescence. Applied Optics, 43, 4488-4496.

Grime, J.P. (1973) Competitive exclusion in herbaceous vegetation. Nature, 242, 344.

Hartikainen, S.M., Jach, A., Grané, A. \& Robson, T.M. (2018) Assessing scale-wise similarity of curves with a thick pen: As illustrated through comparisons of spectral irradiance. Journal of Ecology and Evolution, 8, 10206-10218.

He, P., Wright, I.J., Zhu, S., Onoda, Y., Liu, H., Li, R., Liu, X., Hua, L., Oyanoghafo, O.O. \& Ye, Q. (2019) Leaf mechanical strength and photosynthetic capacity vary independently across 57 subtropical forest species with contrasting light requirements. New Phytologist, 223, 607-618.

Hendry, A.P. (2016) Key questions on the role of phenotypic plasticity in eco-evolutionary dynamics. Journal of Heredity, 107, 25-41.

Hertel, C., Leuchner, M., Rotzer, T. \& Menzel, A. (2012) Assessing stand structure of beech and spruce from measured spectral radiation properties and modeled leaf biomass parameters. Agricultural and Forest Meteorology, 165, 82-91.

Hogewoning, S.W., Trouwborst, G., Maljaars, H., Poorter, H., van Ieperen, W. \& Harbinson, J. (2010) Blue light dose-responses of leaf photosynthesis, morphology, and chemical composition of Cucumis sativus grown under different combinations of red and blue light. Journal of Experimental Botany, 61, 3107-3117.

Hothorn, T., Bretz, F. \& Westfall, P. (2008) Simultaneous inference in general parametric models. Biometrical Journal: Journal of Mathematical Methods in Biosciences, 50, 346-363.

Huche-Thelier, L., Crespel, L., Le Gourrierec, J., Morel, P., Sakr, S. \& Leduc, N. (2016) Light signaling and plant responses to blue and UV radiations-Perspectives for applications in horticulture. Environmental and Experimental Botany, 121, 22-38.

Iiyama, K. \& Wallis, A.F. (1990) Determination of lignin in herbaceous plants by an improved acetyl bromide procedure. Journal of the Science of Food and Agriculture, 51, 145-161.

Jansen, M.A., Bilger, W., Hideg, É., Strid, Å., UV4Plants, W.P. \& Urban, O. (2019) Interactive effects of UV-B radiation in a complex environment. Plant Physiology and Biochemistry, $134,1-8$.

Jenkins, G.I. (2017) Photomorphogenic responses to ultraviolet-B light. Plant, Cell \& Environment, 40, 2544-2557.

This article is protected by copyright. All rights reserved 
Julkunen-Tiitto, R. (1985) Phenolic constituents in the leaves of northern willows: methods for the analysis of certain phenolics. Journal of Agricultural and Food Chemistry, 33, 213-217.

Kitajima, K. (1994) Relative importance of photosynthetic traits and allocation patterns as correlates of seedling shade tolerance of 13 tropical trees. Oecologia, 98, 419-428.

Kitajima, K. \& Poorter, L. (2010) Tissue-level leaf toughness, but not lamina thickness, predicts sapling leaf lifespan and shade tolerance of tropical tree species. New phytologist, 186, 708-721.

Kumar, P., Chen, H.Y.H., Thomas, S.C. \& Shahi, C. (2018) Linking resource availability and heterogeneity to understorey species diversity through succession in boreal forest of Canada. Journal of Ecology, 106, 1266-1276.

Legendre, P. \& Legendre, L.F. (2012) Numerical ecology. Elsevier, Amsterdam.

Lei, T.T. \& Lechowicz, M.J. (1998) Diverse responses of maple saplings to forest light regimes. Annals of Botany, 82, 9-19.

Leuchner, M., Hertel, C. \& Menzel, A. (2011) Spatial variability of photosynthetically active radiation in European beech and Norway spruce. Agricultural and Forest Meteorology, 151, 1226-1232.

Lin, C. (2000) Plant blue-light receptors. Trends in Plant Science, 5, 337-342.

Liu, B., Liu, Q., Daryanto, S., Guo, S., Huang, Z., Wang, Z., Wang, L. \& Ma, X. (2018) Responses of Chinese fir and Schima superba seedlings to light gradients: Implications for the restoration of mixed broadleaf-conifer forests from Chinese fir monocultures. Forest Ecology and Management, 419-420, 51-57.

Mazza, C.A., Boccalandro, H.E., Giordano, C.V., Battista, D., Scopel, A.L. \& Ballare, C.L. (2000) Functional significance and induction by solar radiation of ultraviolet-absorbing sunscreens in field-grown soybean crops. Plant Physiology, 122, 117-125.

Morales, L.O., Brosche, M., Vainonen, J., Jenkins, G.I., Wargent, J.J., Sipari, N., Strid, A., Lindfors, A.V., Tegelberg, R. \& Aphalo, P.J. (2013) Multiple roles for UV RESISTANCE LOCUS8 in regulating gene expression and metabolite accumulation in Arabidopsis under solar ultraviolet radiation. Plant Physiology, 161, 744-759.

Murchie, E.H. \& Lawson, T. (2013) Chlorophyll fluorescence analysis: a guide to good practice and understanding some new applications. Journal of Experimental Botany, 64, 3983-3998.

This article is protected by copyright. All rights reserved 
Navrátil, M., Špunda, V., Marková, I. \& Janouš, D. (2007) Spectral composition of photosynthetically active radiation penetrating into a Norway spruce canopy: the opposite dynamics of the blue/red spectral ratio during clear and overcast days. Trees, 21, 311-320.

Niinemets, U. \& Kull, O. (1998) Stoichiometry of foliar carbon constituents varies along light gradients in temperate woody canopies: implications for foliage morphological plasticity. Tree Physiology, 18, 467-479.

Niinemets, Ü. \& Valladares, F. (2004) Photosynthetic acclimation to simultaneous and interacting environmental stresses along natural light gradients: optimality and constraints. Plant Biology, 6, 254-268.

O'Hara, A., Headland, L.R., Díaz-Ramos, L.A., Morales, L.O., Strid, Å. \& Jenkins, G.I. (2019) Regulation of Arabidopsis gene expression by low fluence rate UV-B independently of UVR8 and stress signaling. Photochemical \& Photobiological Sciences, 18, 1675-1684.

Oguchi, R., Hiura, T. \& Hikosaka, K. (2017) The effect of interspecific variation in photosynthetic plasticity on 4-year growth rate and 8-year survival of understorey tree seedlings in response to gap formations in a cool-temperate deciduous forest. Tree Physiology, 37, 1113-1127.

Oksanen, J., Blanchet, F., Friendly, M., Kindt, R., Legendre, P., McGlinn, D., Minchin, P., O’Hara, R., Simpson, G. \& Solymos, P. (2018) vegan: Community Ecology Package. R package version 2.5-2. 2018.

Pearcy, R.W. (1994) Photosynthetic utilization of sunflecks: a temporally patchy resource on a time scale of seconds to minutes. Exploitation of environmental heterogeneity by plants, 175-208.

Pearcy, R.W. \& Calkin, H.W. (1983) Carbon dioxide exchange of C3 and C4 tree species in the understory of a Hawaiian forest. Oecologia, 58, 26-32.

Pearcy, R.W., Muraoka, H. \& Valladares, F. (2005) Crown architecture in sun and shade environments: assessing function and trade-offs with a three-dimensional simulation model. New Phytologist, 166, 791-800.

Perez-Ramos, I.M., Matias, L., Gomez-Aparicio, L. \& Godoy, O. (2019) Functional traits and phenotypic plasticity modulate species coexistence across contrasting climatic conditions. Nature Communications, 10, 2555. https://doi.org/2510.1038/s41467-41019-10453-41460.

This article is protected by copyright. All rights reserved 
Pescheck, F. \& Bilger, W. (2019). High impact of seasonal temperature changes on acclimation of photoprotection and radiation-induced damage in field grown Arabidopsis thaliana. Plant Physiology and Biochemistry 134, 129-136.

Pinheiro, J.C. \& Bates, D.M. (2000) Linear mixed-effects models: basic concepts and examples. $J$ Mixed-effects models in SS-Plus, 3-56.

Poorter, H., Niinemets, U., Ntagkas, N., Siebenkas, A., Maenpaa, M., Matsubara, S. \& Pons, T. (2019) A meta-analysis of plant responses to light intensity for 70 traits ranging from molecules to whole plant performance. New Phytologist.

Portsmuth, A. \& Niinemets, U. (2007) Structural and physiological plasticity in response to light and nutrients in five temperate deciduous woody species of contrasting shade tolerance. Functional Ecology, 21, 61-77.

Power, S.C., Verboom, G.A., Bond, W.J. \& Cramer, M.D. (2019) Does a trade-off between trait plasticity and resource conservatism contribute to the maintenance of alternate stable states? New Phytologist, 223, 1809-1819

Rai, N., Neugart, S., Yan, Y., Wang, F., Siipola, S.M., Lindfors, A.V., Winkler, J.B., Albert, A., Brosché, M. \& Lehto, T. (2019) How do cryptochromes and UVR8 interact in natural and simulated sunlight? Journal of Experimental Botany, 18, 4975-4990.

Revell LJ. 2012. phytools: an R package for phylogenetic comparative biology (and other things). Methods in Ecology and Evolution 3: 217-223.

Riikonen, J., Kettunen, N., Gritsevich, M., Hakala, T., Sarkka, L. \& Tahvonen, R. (2016) Growth and development of Norway spruce and Scots pine seedlings under different light spectra. Environmental and Experimental Botany, 121, 112-120.

Sarala, M., Taulavuori, E., Karhu, J., Savonen, E.M., Laine, K., Kubin, E. \& Taulavuori, K. (2009) Improved elongation of Scots pine seedlings under blue light depletion is not dependent on resource acquisition. Functional Plant Biology, 36, 742-751.

Schlichting, C.D. \& Pigliucci, M. (1998) Phenotypic evolution: a reaction norm perspective. Sinauer Associates Incorporated.

Searles, P.S., Flint, S.D. \& Caldwell, M.M. (2001) A meta analysis of plant field studies simulating stratospheric ozone depletion. Oecologia, 127, 1-10.

Shinomura, T., Nagatani, A., Hanzawa, H., Kubota, M., Watanabe, M. \& Furuya, M. (1996) Action spectra for phytochrome A-and B-specific photoinduction of seed germination in Arabidopsis thaliana. Proceedings of the National Academy of Sciences, 93, 8129-8133.

This article is protected by copyright. All rights reserved 
Siipola, S.M., Kotilainen, T., Sipari, N., Morales, L.O., Lindfors, A.V., ROBSON, T. \& Aphalo, P.J. (2015) Epidermal UV-A absorbance and whole-leaf flavonoid composition in pea respond more to solar blue light than to solar UV radiation. Plant, Cell and Environment, 38, 941-952.

Smith, H. (2000) Phytochromes and light signal perception by plants - an emerging synthesis. Nature, 407, 585-591.

Smith, H.L., McAusland, L. \& Murchie, E.H. (2017) Don't ignore the green light: exploring diverse roles in plant processes. Journal of Experimental Botany, 68, 2099-2110.

Terashima, I., Fujita, T., Inoue, T., Chow, W.S. \& Oguchi, R. (2009) Green light drives leaf photosynthesis more efficiently than red light in strong white light: revisiting the enigmatic question of why leaves are green. Plant and Cell Physiology, 50, 684-697.

Turcotte, M.M. \& Levine, J.M. (2016) Phenotypic plasticity and species coexistence. Trends in Ecology \& Evolution, 31, 803-813.

Turnbull, T.L., Barlow, A.M. \& Adams, M.A. (2013) Photosynthetic benefits of ultraviolet-A to Pimelea ligustrina, a woody shrub of sub-alpine Australia. Oecologia, 173, 375-385.

Valladares, F., Balaguer, L., Martinez-Ferri, E., Perez-Corona, E. \& Manrique, E. (2002a) Plasticity, instability and canalization: is the phenotypic variation in seedlings of sclerophyll oaks consistent with the environmental unpredictability of Mediterranean ecosystems? New Phytologist, 156, 457-467.

Valladares, F., Chico, J.M., Aranda, I., Balaguer, L., Dizengremel, P., Manrique, E. \& Dreyer, E. (2002b) The greater seedling high-light tolerance of Quercus robur over Fagus sylvatica is linked to a greater physiological plasticity. Trees-Structure and Function, 16, 395-403.

Valladares, F., Laanisto, L., Niinemets, Ü. \& Zavala, M.A. (2016) Shedding light on shade: ecological perspectives of understorey plant life. Plant Ecology \& Diversity, 9, 237-251.

Valladares, F. \& Niinemets, U. (2008) Shade tolerance, a key plant feature of complex nature and consequences. Annual Review of Ecology Evolution and Systematics, 39, 237-257.

Valladares, F., Wright, S.J., Lasso, E., Kitajima, K. \& Pearcy, R.W. (2000) Plastic phenotypic response to light of 16 congeneric shrubs from a Panamanian rainforest. Ecology, 81, 1925-1936.

Wade, H.K., Sohal, A.K. \& Jenkins, G.I. (2003) Arabidopsis ICX1 is a negative regulator of several pathways regulating flavonoid biosynthesis genes. Plant Physiology, 131, 707-715.

This article is protected by copyright. All rights reserved 
Wang, Q.-W., Hidema, J. \& Hikosaka, K. (2014) Is UV-induced DNA damage greater at higher elevation? . American Journal of Botany, 101, 796-802.

Wang, Q.-W., Kamiyama, C., Hidema, J. \& Hikosaka, K. (2016) Ultraviolet-B-induced DNA damage and ultraviolet-B tolerance mechanisms in species with different functional groups coexisting in subalpine moorlands. Oecologia, 181, 1069-1082.

Waterman, P.G. \& Mole, S. (1994) Analysis of phenolic plant metabolites. Blackwell Scientific.

Way, D.A. \& Pearcy, R.W. (2012) Sunflecks in trees and forests: from photosynthetic physiology to global change biology. Tree Physiology, 32, 1066-1081.

Westerband, A.C., Horvitz, C.C. \& Gilliam, F. (2017) Early life conditions and precipitation influence the performance of widespread understorey herbs in variable light environments. Journal of Ecology, 105, 1298-1308.

Zhang, T., Maruhnich, S.A. \& Folta, K.M. (2011) Green light induces shade avoidance symptoms. Plant physiology, 157, 1528-1536.

This article is protected by copyright. All rights reserved 
Table 1 List of plant traits measured in the spectral irradiance experiment and categorized according to their function.

\begin{tabular}{|c|c|c|c|c|c|}
\hline Cate. & No. & $\begin{array}{l}\text { Trait } \\
\text { code }\end{array}$ & Full name & Explanations (unit) & Trait functions \\
\hline \multirow{5}{*}{ 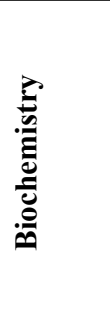 } & 1 & Pheno & Total phenolics & Leaf total phenolics content per unit dry mass $\left(\mathrm{mg} \mathrm{g}^{-1}\right)$ & Chemical defense, palatability, decomposability \\
\hline & 2 & Lignin & Lignin & Leaf lignin content per unit dry mass $\left(\mathrm{mg} \mathrm{g}^{-1}\right)$ & Chemical defense, palatability, decomposability \\
\hline & 3 & Tannin & Condensed tannins & Leaf condensed tannin content per unit dry mass $\left(\mathrm{mg} \mathrm{g}^{-1}\right)$ & Chemical defense, palatability, decomposability \\
\hline & 4 & Flavo & Flavonols & $\begin{array}{l}\text { Leaf adaxial flavonols measured by Dualex (absorbance unit, AU leaf } \\
\text { area-1 }^{-1} \text { ) }\end{array}$ & Chemical defense, palatability, decomposability \\
\hline & 5 & Antho & Anthocyanin & Leaf adaxial anthocyanin measured by Dualex (AU leaf area-1) & Chemical defense, palatability, decomposability \\
\hline \multirow{5}{*}{$\begin{array}{l}\frac{20}{00} \\
\frac{0}{0} \\
\frac{0}{20} \\
\frac{1}{2}\end{array}$} & 6 & Chl & Chlorophyll & Leaf chlorophyll content measured by Dualex (AU leaf area ${ }^{-1}$ ) & Photosynthetic capacity \\
\hline & 7 & $\mathrm{~N}$ & Nitrogen & Leaf nitrogen content per unit leaf mass ( $\left.\mathrm{mg} \mathrm{g}^{-1}\right)$ & Photosynthetic capacity, palatability, decomposability \\
\hline & 8 & $\mathrm{C} / \mathrm{N}$ & Carbon nitrogen ratio & Ratio of leaf carbon to nitrogen content & $\begin{array}{l}\text { Function balance signaling, adaption to light, palatability, } \\
\text { decomposability }\end{array}$ \\
\hline & 9 & $F_{\mathrm{q}} / F_{\mathrm{m}}{ }^{\prime}$ & Effective quantum yield of PSII & $\begin{array}{l}\text { Leaf } F_{\mathrm{q}} / F_{\mathrm{m}} \text { 'or } \Phi \text { PSII measured in the actual light of the plant, giving } \\
\text { the effective quantum yield of photosystem II photochemistry }\end{array}$ & $\begin{array}{l}\text { Photosynthetic capacity, photoinhibition, capacity to dissipate } \\
\text { light energy, responsiveness to light quality }\end{array}$ \\
\hline & 10 & $F_{\mathrm{v}} / F_{\mathrm{m}}$ & Maximum quantum yield of PSII & $\begin{array}{l}\text { Leaf } F_{\mathrm{v}} / F_{\mathrm{m}} \text { measured by mini-PAM after dark acclimation, giving the } \\
\text { maximum quantum yield of photosystem II photochemistry }\end{array}$ & $\begin{array}{l}\text { Photosynthetic capacity, photodamage, capacity to dissipate } \\
\text { light energy, responsiveness to light quality }\end{array}$ \\
\hline \multirow{5}{*}{$\stackrel{\frac{0}{0}}{\frac{0}{0}}$} & 11 & LeafL & Leaf lamina length & Length of the fully expanded mature leaf lamina $(\mathrm{cm})$ & Photosynthetic capacity, light interception \\
\hline & 12 & LA & Leaf size & Area of the fully expanded mature leaf lamina $\left(\mathrm{cm}^{2}\right)$ & Photosynthetic capacity, light interception \\
\hline & 13 & LDMC & Leaf dry matter content & Calculated from LMA divided by leaf thickness $\left(\mathrm{mg} \mathrm{g}^{-1}\right)$ & Photosynthetic capacity; palatability \\
\hline & 14 & LMA & Leaf mass per area & Leaf mass per unit leaf area $\left(\mathrm{g} \mathrm{m}^{2}\right)$ & Photosynthetic capacity, defense, adaption to light \\
\hline & 15 & LeafT & Leaf lamina strength & $\begin{array}{l}\text { The mean of toughness at the leaf lamina base, middle and tip, } \\
\text { measured using a digital force gauge }\left(\mathrm{N} \mathrm{mm}^{-1}\right)\end{array}$ & Photosynthetic capacity, physical architecture \\
\hline \multirow{2}{*}{$\stackrel{\bar{E}}{\stackrel{2}{3}}$} & 16 & PetioleL\# & Petiole length & The length of the petioles of the expanded mature leaves (mm) & Light interception, competitive ability \\
\hline & 17 & TLA & Total leaf area & The sum of all the leaf area of an individual plant $\left(\mathrm{cm}^{2}\right)$ & Light interception, photosynthetic capacity \\
\hline
\end{tabular}

This article is protected by copyright. All rights reserved 


\begin{tabular}{|c|c|c|c|c|c|c|}
\hline \multirow{3}{*}{$\frac{\pi}{2}$} & \multirow[b]{3}{*}{$\overleftrightarrow{\Xi}$} & 18 & CrownS & Crown spread & $\begin{array}{l}\text { The average lengths of two longest perpendicular spreads from edge } \\
\text { to edge across the crown }(\mathrm{cm})\end{array}$ & Light interception, competitive ability \\
\hline & & $: 19$ & Height & Plant height & Individual maximum height $(\mathrm{cm})$ & Light interception, competitive ability \\
\hline & & 20 & StemD & Stem diameter & Mean stem diameter of two dimensions of an individual ( $\mathrm{mm}$ ) & Light interception, competitive ability \\
\hline \multirow{5}{*}{ 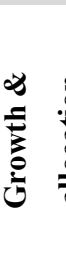 } & \multirow{5}{*}{ 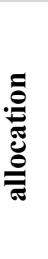 } & 21 & $\mathrm{ABDM}$ & Aboveground drymass & The total dry mass of above organs (g) & Competitive ability, energy reserves \\
\hline & & 22 & BEDM & Below drymass & The total dry mass of roots $(\mathrm{g})$ & Competitive ability, energy reserves \\
\hline & & 23 & TDM & Total drymass & the total dry mass of below- and aboveground ( $\mathrm{g}$ ) & Competitive ability, energy reserves \\
\hline & & 24 & $\mathrm{R} / \mathrm{S}$ & Root shoot ratio & The ratio of the belowground and aboveground dry mass & Competitive ability, responsiveness to light quality \\
\hline & & 25 & RGR* & Relative growth rate & Rate of plant size growth increase per unit day $\left(\mathrm{D}^{2} \mathrm{H}\left(\mathrm{D}^{2} \mathrm{H}\right)^{-1} \mathrm{~d}^{-1}\right)$ & Competitive ability, responsiveness to light quality \\
\hline
\end{tabular}

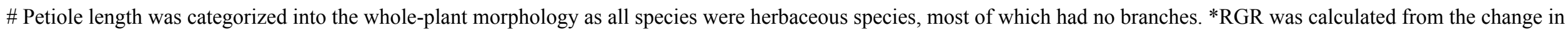

Diameter*Diameter*Height during the treatment duration (see details in Materials and Methods). 
Table 2 Main effects on plant functional traits of the spectral treatment, functional group, and their interaction. The specific effect of each spectral region of solar radiation is given by contrast comparison between pairs of treatments.

\begin{tabular}{|c|c|c|c|c|c|c|c|c|c|c|c|c|c|c|c|c|c|c|c|c|c|c|}
\hline \multirow{3}{*}{ Cate. } & \multirow{3}{*}{ Traits } & \multicolumn{6}{|c|}{ Main effects } & \multirow{3}{*}{ Groups } & \multicolumn{14}{|c|}{ Effects of solar spectral regions (contrast) } \\
\hline & & \multicolumn{2}{|c|}{ Treatment (T) } & \multicolumn{2}{|c|}{ Group (G) } & \multicolumn{2}{|c|}{$\mathbf{G} \times \mathbf{T}$} & & \multicolumn{2}{|c|}{$\begin{array}{c}\mathbf{U V}-\mathbf{B} \\
\text { (treatment } i i \text { vs. } i \text { ) }\end{array}$} & \multicolumn{2}{|c|}{$\begin{array}{c}\text { UV-A } \\
\text { (iii vs. } i i)\end{array}$} & \multicolumn{2}{|c|}{$\begin{array}{c}\text { Blue } \\
(i v \text { vs. } i i i) \\
\end{array}$} & \multicolumn{2}{|c|}{$\begin{array}{c}\text { Green } \\
(v \text { vs. } i v)\end{array}$} & \multicolumn{2}{|c|}{$\begin{array}{c}\mathbf{U V} \\
\text { (iii vs. } i) \\
\end{array}$} & \multicolumn{2}{|c|}{$\begin{array}{c}\text { BG } \\
(v \text { vs. } i i i)\end{array}$} & \multicolumn{2}{|c|}{$\begin{array}{l}\mathbf{U V}-\mathbf{B G} \\
(v \text { vs. } i)\end{array}$} \\
\hline & & $\chi^{2}$ & $P$ & $\chi^{2}$ & $P$ & $\chi^{2}$ & $P$ & & $Z$ & $P$ & $Z$ & $P$ & $Z$ & $P$ & 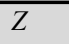 & $P$ & $Z$ & $P$ & $Z$ & $P$ & $Z$ & $P$ \\
\hline \multirow{8}{*}{ 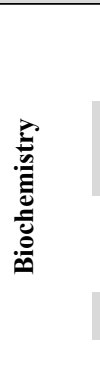 } & Pheno.mass* & 41.71 & 40.001 & 0.00 & 0.959 & 2.54 & 0.638 & & -3.41 & 0.004 & 0.07 & 1.000 & -1.34 & 0.604 & -1.48 & 0.514 & -3.35 & 0.005 & -2.77 & 0.033 & -6.14 & $<0.001$ \\
\hline & Pheno.area\# & 46.38 & $<0.001$ & 0.17 & 0.677 & 0.37 & 0.985 & & -3.38 & 0.005 & 0.78 & 0.915 & -0.16 & 1.000 & -2.42 & 0.085 & 4.13 & $<0.001$ & -2.51 & 0.067 & -6.66 & $<0.001$ \\
\hline & Lignin.mass* & 11.96 & 0.018 & 0.12 & 0.726 & 4.16 & 0.385 & & 2.40 & 0.090 & -1.17 & 0.720 & -2.03 & 0.204 & 1.00 & 0.818 & -1.22 & 0.685 & -1.00 & 0.817 & 0.18 & 1.000 \\
\hline & Lignin.area\# & 32.13 & $<0.001$ & 1.09 & 0.296 & 3.60 & 0.463 & & -0.89 & 0.868 & 1.55 & 0.464 & -0.33 & 0.996 & -2.53 & 0.065 & 2.43 & 0.083 & -2.75 & 0.036 & -5.23 & $<0.001$ \\
\hline & Tannin.mass* & 15.80 & 0.003 & 0.26 & 0.610 & 1.49 & 0.828 & & 0.03 & 1.000 & -1.02 & 0.803 & 0.11 & 1.000 & -2.66 & 0.046 & -1.00 & 0.814 & -2.43 & 0.082 & -3.53 & 0.003 \\
\hline & Tannin.area\# & 22.36 & $<0.001$ & 0.86 & 0.354 & 2.73 & 0.604 & & -0.12 & 1.000 & 1.42 & 0.549 & 0.21 & 0.999 & -2.93 & 0.021 & 1.55 & 0.464 & -2.60 & 0.053 & -4.24 & $<0.001$ \\
\hline & Flavo & 100.59 & $<.001$ & 20.47 & $<0.001$ & 2.88 & 0.579 & & -2.81 & 0.030 & -2.03 & 0.207 & 0.09 & 1.000 & -0.29 & 0.998 & -4.81 & $<0.001$ & -0.20 & 1.000 & -5.00 & $<0.001$ \\
\hline & Antho & 15.65 & 0.004 & 14.50 & $<0.001$ & 7.69 & 0.104 & & -0.33 & 0.997 & 0.64 & 0.956 & 2.42 & 0.084 & -0.60 & 0.966 & 0.32 & 0.997 & 1.76 & 0.336 & 2.13 & 0.166 \\
\hline \multirow{6}{*}{ 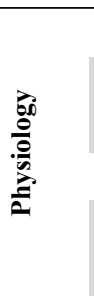 } & Chl & 11.94 & 0.018 & 9.60 & 0.002 & 4.15 & 0.386 & & -0.21 & 0.999 & 0.38 & 0.994 & -1.36 & 0.592 & -0.94 & 0.850 & 0.59 & 0.968 & -2.25 & 0.127 & -2.89 & 0.023 \\
\hline & N.mass* & 69.77 & $<.001$ & 0.03 & 0.868 & 5.09 & 0.278 & & 1.55 & 0.466 & -0.76 & 0.923 & -3.00 & 0.017 & 4.77 & $<0.001$ & -2.29 & 0.117 & -7.50 & $<0.001$ & -5.52 & $<0.001$ \\
\hline & N.area\# & 116.49 & $<0.001$ & 2.42 & 0.120 & 0.57 & 0.967 & & -1.51 & 0.490 & 1.06 & 0.779 & -2.01 & 0.214 & -5.54 & $<0.001$ & 2.55 & 0.061 & -7.27 & $<0.001$ & -10.06 & $<0.001$ \\
\hline & $\mathrm{C} / \mathrm{N}$ & 32.32 & $<0.001$ & 0.00 & 0.978 & 5.88 & 0.209 & & -1.43 & 0.540 & 1.52 & 0.486 & 1.53 & 0.474 & 3.91 & $<0.001$ & 2.95 & 0.020 & 5.28 & $<0.001$ & 2.56 & 0.060 \\
\hline & $\mathrm{Fq} / \mathrm{Fm}^{\prime}$ & 15.11 & 0.004 & 30.96 & $<0.001$ & 6.11 & 0.191 & & -1.07 & 0.782 & 1.25 & 0.666 & -2.70 & 0.041 & -0.19 & 1.000 & 0.19 & 1.000 & -2.93 & 0.021 & -2.75 & 0.035 \\
\hline & $\mathrm{Fv} / \mathrm{Fm}$ & 5.01 & 0.286 & 10.54 & 0.001 & 8.21 & 0.084 & & & & & & & & & & & & & & & \\
\hline \multirow{5}{*}{ 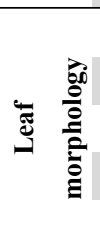 } & LeafL & $\begin{array}{l}17.19 \\
\end{array}$ & 0.002 & 0.02 & 0.897 & 2.08 & \begin{tabular}{ll|}
0.721 \\
\end{tabular} & & -0.47 & 0.986 & -2.26 & 0.125 & 0.17 & 1.000 & -0.63 & 0.959 & -2.79 & 0.032 & -0.46 & 0.987 & -3.23 & 0.008 \\
\hline & LA & 32.25 & $<0.001$ & 0.01 & 0.938 & 5.06 & 0.281 & & -1.46 & 0.522 & -1.57 & 0.454 & -0.46 & 0.987 & -1.74 & 0.346 & -3.03 & 0.015 & -2.13 & 0.166 & -5.19 & $<0.001$ \\
\hline & LDMC & 17.73 & 0.001 & 2.15 & 0.142 & 1.19 & 0.880 & & -1.29 & 0.633 & -1.04 & 0.794 & 2.11 & 0.172 & -3.43 & 0.004 & -2.31 & 0.110 & -1.31 & 0.622 & -3.63 & 0.002 \\
\hline & LMA & 58.39 & $<0.001$ & 1.63 & 0.201 & 1.63 & 0.803 & & -3.31 & 0.006 & -1.08 & 0.773 & 0.43 & 0.990 & -3.72 & 0.002 & -4.33 & $<0.001$ & -3.19 & 0.009 & -7.58 & $<0.001$ \\
\hline & LeafT & 6.74 & 0.150 & 0.67 & 0.414 & 0.35 & 0.987 & & & & & & & & & & & & & & & \\
\hline \multirow{3}{*}{$\stackrel{\frac{\bar{d}}{g}}{\frac{\bar{d}}{3}}$} & PetioleL & $\begin{array}{l}18.29 \\
\end{array}$ & 0.001 & 0.38 & 0.540 & 2.76 & 0.599 & & -0.21 & 0.999 & -2.35 & 0.102 & 3.27 & 0.007 & 0.85 & 0.890 & $\begin{array}{l}-2.62 \\
\end{array}$ & 0.051 & 4.03 & $<0.001$ & 1.53 & 0.475 \\
\hline & TLA & 40.52 & $<0.001$ & 0.08 & 0.782 & 22.49 & $<0.001$ & Intolerant & -1.99 & 0.390 & -1.44 & 0.785 & -0.82 & 0.990 & -1.81 & 0.518 & -3.43 & 0.008 & -2.51 & 0.130 & -6.02 & $<0.001$ \\
\hline & & & & & & & & Tolerant & -2.95 & 0.039 & -0.90 & 0.981 & 1.88 & 0.470 & 1.57 & 0.698 & -3.64 & 0.004 & 3.30 & 0.013 & -0.10 & 1.000 \\
\hline
\end{tabular}

This article is protected by copyright. All rights reserved 


\begin{tabular}{|c|c|c|c|c|c|c|c|c|c|c|c|c|c|c|c|c|c|c|c|c|c|c|}
\hline \multirow[b]{6}{*}{$\mathbf{\Xi}$} & CrownS $\left(1^{\text {st }}\right)$ & 22.20 & $<0.001$ & 14.44 & $<0.001$ & 8.26 & 0.083 & & -1.83 & 0.301 & -1.13 & 0.745 & 1.15 & 0.731 & -2.61 & 0.052 & -3.00 & 0.017 & -1.46 & 0.526 & -4.49 & $<0.001$ \\
\hline & CrownS (final) & 44.61 & $<0.001$ & 9.20 & 0.002 & 7.62 & 0.106 & & -3.66 & 0.002 & -1.00 & 0.816 & -0.67 & 0.949 & -0.48 & 0.985 & -4.64 & $<0.001$ & -1.13 & 0.741 & -5.84 & $<0.001$ \\
\hline & Height $\left(1^{\text {st }}\right)$ & 15.61 & 0.004 & 10.77 & 0.001 & 2.77 & 0.597 & & -1.09 & 0.765 & 0.58 & 0.970 & 2.33 & 0.105 & 0.23 & 0.999 & -0.51 & 0.981 & 2.57 & 0.058 & 2.10 & 0.179 \\
\hline & Height (final) & 4.99 & 0.288 & 6.58 & 0.010 & 0.84 & 0.933 & & & & & & & & & & & & & & & \\
\hline & StemD $\left(1^{\text {st }}\right)$ & 5.65 & 0.227 & 3.77 & 0.052 & 7.10 & 0.131 & & & & & & & & & & & & & & & \\
\hline & StemD (final) & 7.82 & 0.099 & 2.75 & 0.097 & 3.78 & 0.437 & & & & & & & & & & & & & & & \\
\hline \multirow{9}{*}{ 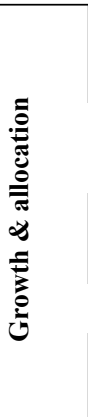 } & ABDM & 60.59 & $<0.001$ & 0.14 & 0.706 & 19.50 & 0.001 & Intolerant & -1.68 & 0.622 & -3.09 & 0.025 & 2.02 & 0.373 & -2.32 & 0.203 & -4.85 & $<0.001$ & -0.32 & 1.000 & -5.12 & $<0.001$ \\
\hline & & & & & & & & Tolerant & -2.10 & 0.326 & -0.27 & 1.000 & 2.67 & 0.086 & 0.33 & 1.000 & -2.23 & 0.251 & 2.87 & 0.048 & 0.79 & 0.992 \\
\hline & BEDM & 52.18 & $<0.001$ & 0.06 & 0.811 & 16.95 & 0.002 & Intolerant & -2.73 & 0.038 & -3.77 & 0.001 & 0.92 & 0.855 & 0.95 & 0.840 & -6.58 & $<0.001$ & 1.80 & 0.315 & -4.62 & $<0.001$ \\
\hline & & & & & & & & Tolerant & -1.94 & 0.246 & -0.66 & 0.951 & 2.58 & 0.056 & -0.25 & 0.999 & -2.47 & 0.076 & 2.30 & 0.113 & 0.08 & 1.000 \\
\hline & TDM & 41.59 & $<0.001$ & 0.07 & 0.788 & 21.51 & $<0.001$ & Intolerant & -2.00 & 0.386 & -3.41 & 0.008 & 1.95 & 0.423 & -1.85 & 0.491 & -5.51 & $<0.001$ & 0.07 & 1.000 & -5.37 & $<0.001$ \\
\hline & & & & & & & & Tolerant & -2.32 & 0.205 & -0.40 & 1.000 & 2.98 & 0.035 & 0.23 & 1.000 & -2.57 & 0.114 & 3.10 & 0.024 & 0.68 & 0.997 \\
\hline & $\mathrm{R} / \mathrm{S}$ & 19.22 & 0.001 & 0.49 & 0.486 & 3.40 & 0.493 & & -1.85 & 0.344 & -1.85 & 0.287 & -0.14 & 1.000 & 1.31 & 0.627 & -3.56 & 0.003 & 1.13 & 0.737 & -2.32 & 0.107 \\
\hline & RGR $\left(1^{\text {st }}\right)$ & 3.60 & 0.462 & 64.85 & $<0.001$ & 9.26 & 0.055 & & & & & & & & & & & & & & & \\
\hline & RGR (final) & 3.98 & 0.408 & 43.17 & $<0.001$ & 2.16 & 0.707 & & & & & & & & & & & & & & & \\
\hline
\end{tabular}

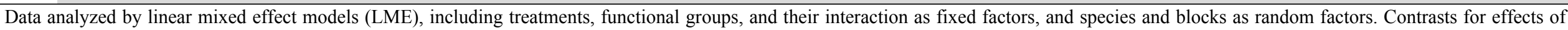

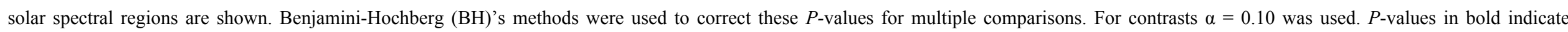

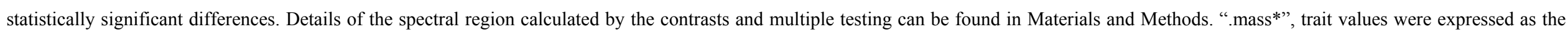
percent per unit dry mass, and ".area\#”, trait values were expressed as the gram per unit dry mass. Full names of plant trait are in Table 1.

This article is protected by copyright. All rights reserved 


\section{Figure legends}

Fig. 1 Experiment with filters attenuating solar spectral irradiance. a) Photograph of the experiment testing the effects of spectral composition on traits from 23 plant species of two functional groups. b) Spectral photon irradiance of ambient solar radiation and under our selectively attenuating filters: [transmitting (i) $>280 \mathrm{~nm}$ (polythene); (ii) $>315 \mathrm{~nm}$ (polyester); (iii) > $400 \mathrm{~nm}($ Rosco \#226); (iv) >500 nm (Roscolux \#312); (v) > $580 \mathrm{~nm}($ Rosco \#135)]. c) Actual spectral irradiance measured under our filter treatments at solar noon when filters were combined with shade mesh, used to equalize PAR under all treatments. The inset in a) indicates the layout of filter frames in the common-garden experiment; the filter types $(i) \sim(v)$ were consistent with those in c). The y-axis of both b) and c) gives spectral photon irradiance in units of $\mu \mathrm{mol} \mathrm{m} \mathrm{m}^{-2} \mathrm{~s}^{-1}$, but because of the shade mesh the irradiance is lower in c), up to 3 instead of 30 $\mu \mathrm{mol} \mathrm{m} \mathrm{m}^{-2} \mathrm{~s}^{-1}$. See Materials and Methods for further details.

Fig. 2 Variation in plant traits under different spectral irradiance treatments according to plant functional type. The $x$-axis shows which wavelength regions in each treatment were attenuated (-) and transmitted ( + ) under the filters. The filter type $i \sim v$ was consistent with that in Fig.1. The contrasts between pairs of treatments are given in the bottom left, as UV-B, UV-A, Blue, Green. Each point represents the mean \pm 1 SE trait value of the individuals of each functional group. Light blue squares represent shade-tolerant species and orange circles represent shade-intolerant species. Where names of the plant traits given on the y-axis are abbreviated, their full names can be found in Table 1. Detailed results and statistical analyses can be found in Table 2 including effects of single and multiple spectral regions.

Fig. 3 Plant traits plasticity of response to different spectral regions of solar radiation. The fraction was calculated from the contrasts between spectral treatments in Fig. 2. a) g), contrast comparisons for each spectral region; h), average plasticity of all plant traits for each spectral region. Bars (mean $\pm 1 \mathrm{SE}, \mathrm{n}=9 \sim 11$ shade-intolerant species (orange), 3 12 shade-tolerant species (light blue)) for each treatment are arranged by increasing mean plasticity of shade-intolerant species. n.s., no statistically significant difference $(P>0.05)$. See Table 2 for the contrast pairs used for analyzing the effects of solar spectral region. Names of the plant traits given on the $x$-axis in a) g) are abbreviated, their full names can be found in Table 1.

This article is protected by copyright. All rights reserved 
Fig. 4 Partial redundancy analysis (pRDA) biplot showing the relationship between plant functional traits and spectral composition in the experiment. a) shade-intolerant species, b) shade-tolerant species. Plants traits are indicated by solid-headed black arrows pointing in the direction of increasing values; spectral regions, including UV-B, UV-A, Blue, Green and Red, are indicated by the open-headed red arrow pointing in the direction of increasing values. The relative effects of realistic spectral compositions (as shown in Table S2) on plant traits are analyzed by Monte Carlo permutation test (forward selection, 999 permutations), with species as the covariate. Spectral regions in the model are indicated with asterisks (significant effect $P<0.05$ ) and plus symbols (insignificant effect $P>0.05$ but selected by the model), and those without symbols were removed from the model (no significant effect $P>0.05$ ). Traits of the same group were shown in the same color. Full names corresponding to the abbreviated trait names in the figures are given in Table 1. Detailed pRDA results refer to Table S4.

This article is protected by copyright. All rights reserved 
Fig. 1
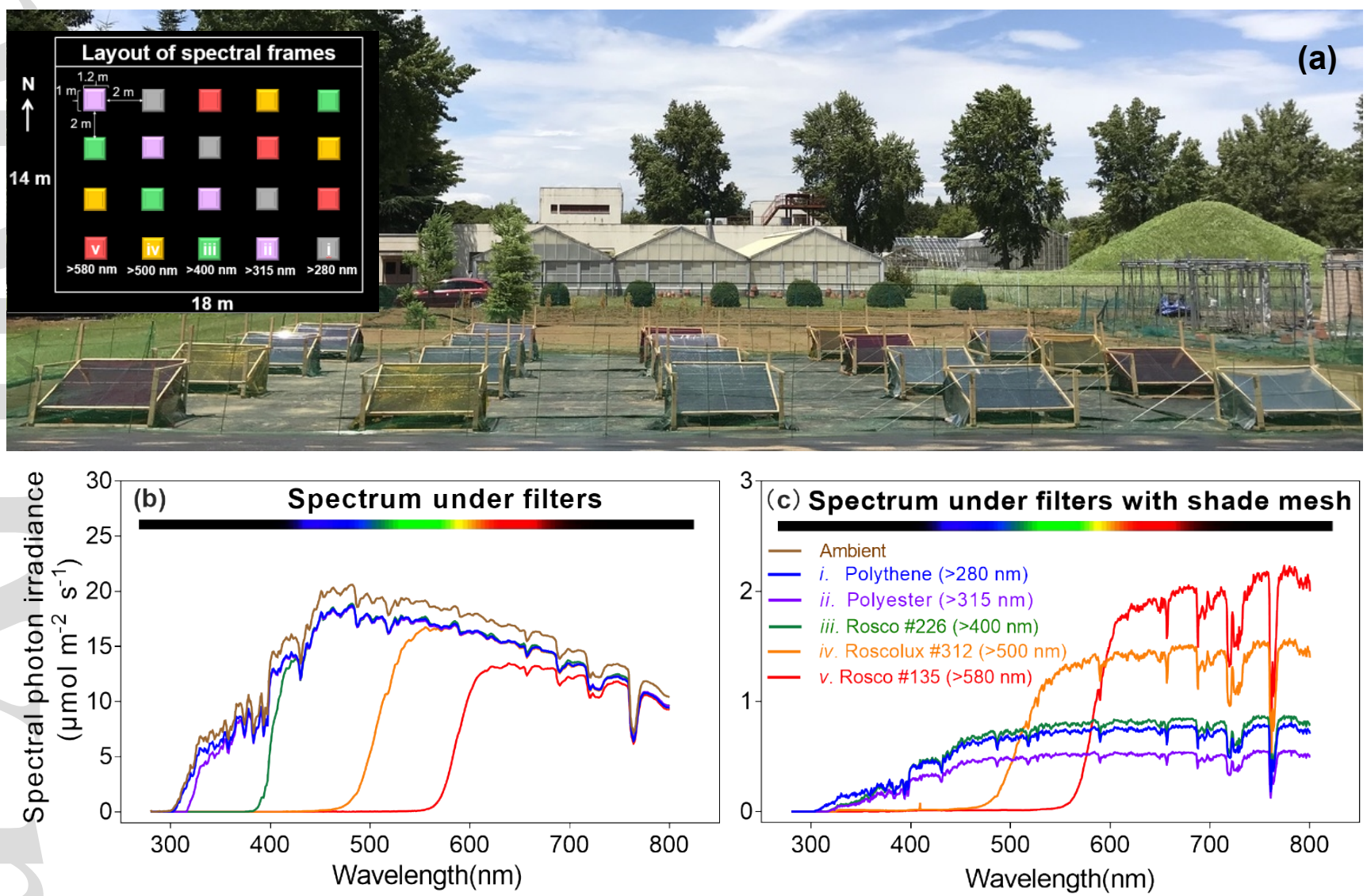

This article is protected by copyright. All rights reserved 


\section{Fig. 2}
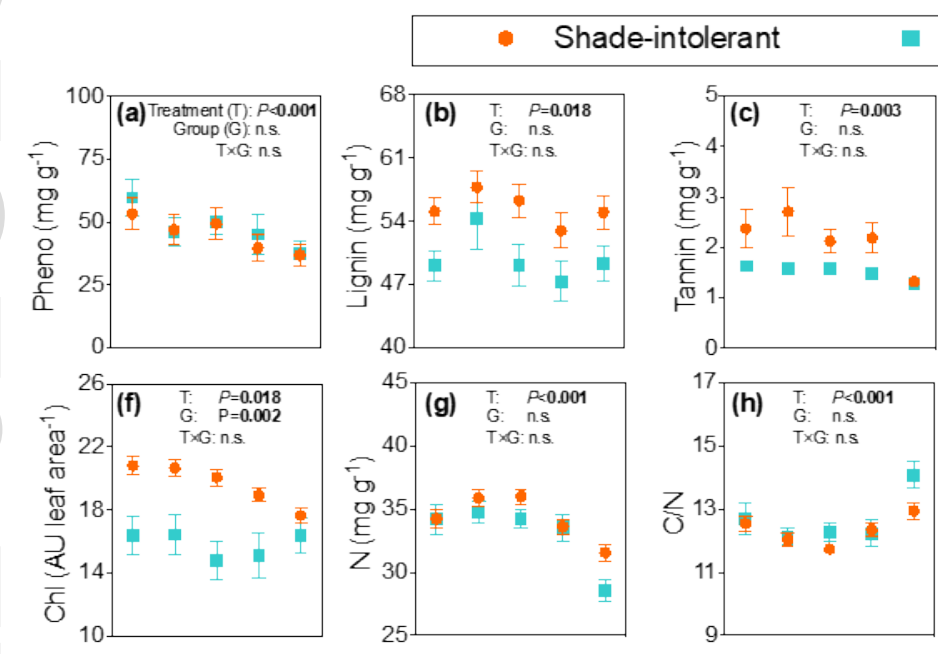

\section{Shade-tolerant}
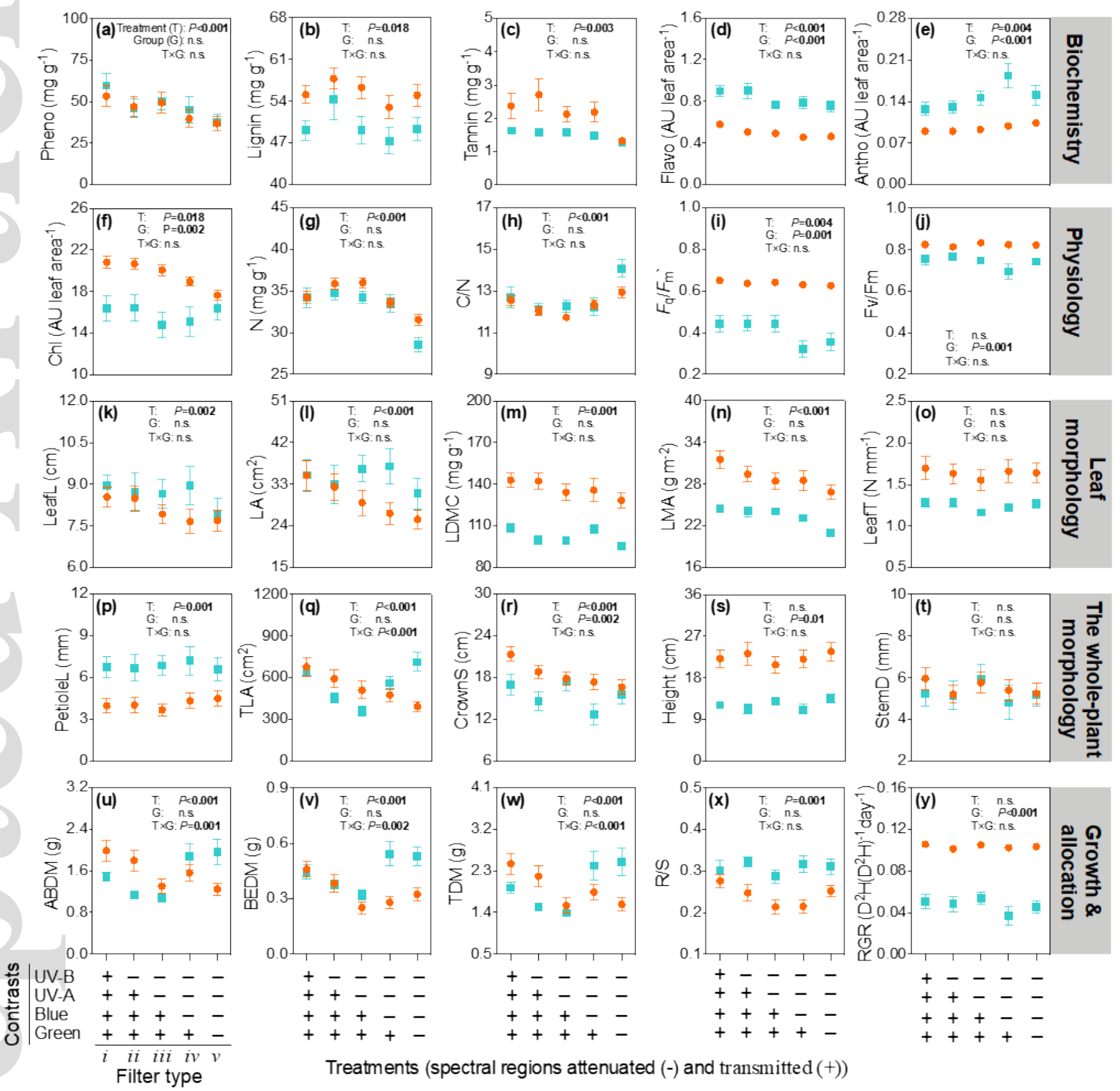

Treatments (spectral regions attenuated $(-)$ and transmitted $(+))$

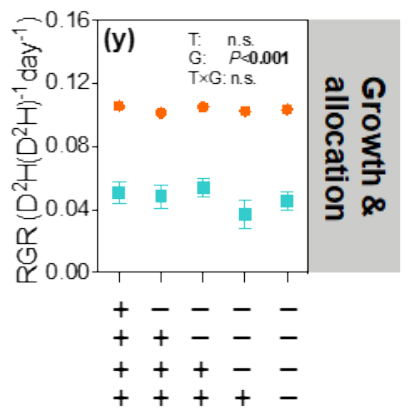

Fig. 3

This article is protected by copyright. All rights reserved 

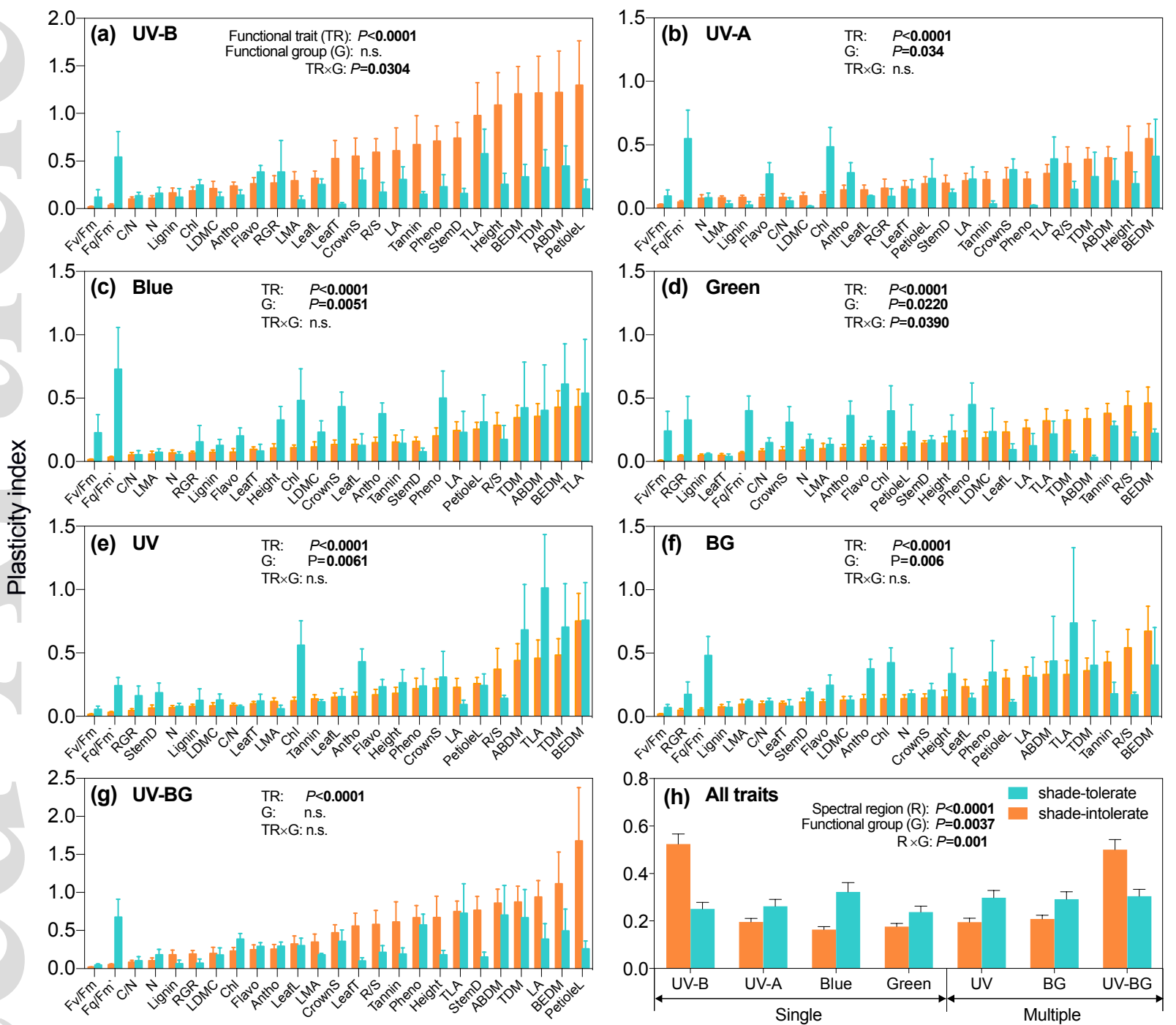

Plant traits

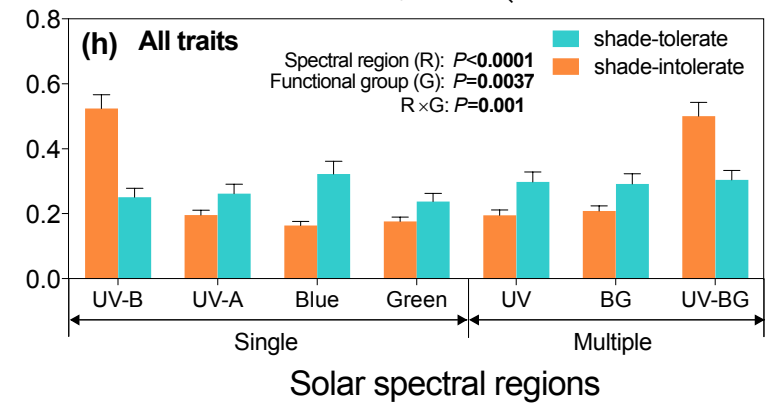

This article is protected by copyright. All rights reserved 
Fig. 4
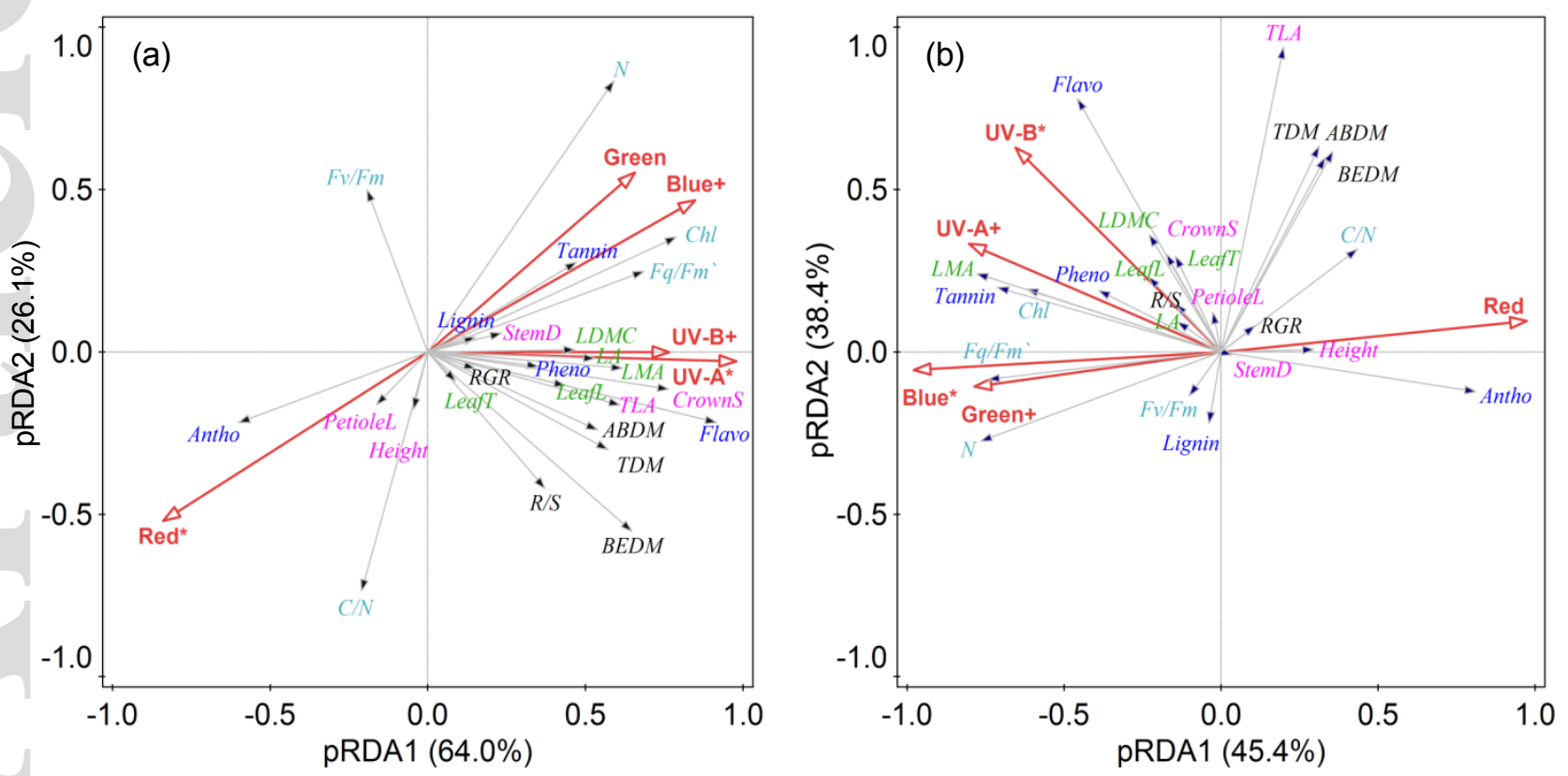

This article is protected by copyright. All rights reserved 